\title{
Rapid Development of Gossamer Propulsion for NASA Inner Solar System Science Missions
}

\author{
by \\ Roy M. Young and Edward E. Montgomery $\mathrm{IV}^{\dagger}$ \\ NASA George C. Marshall Space Flight Center, Huntsville, AL 35812
}

\begin{abstract}
Over a two and one-half year period dating from 2003 through 2005, NASA's In-Space Propulsion Program matured solar sail technology from laboratory components to full systems, demonstrated in as relevant a space environment as could feasibly be simulated on the ground. This paper describes the challenges identified; as well as the approaches taken toward solving a broad set of issues spanning material science, manufacturing technology, and interplanetary trajectory optimization. Revolutionary advances in system structural predictive analysis and characterization testing occurred. Also addressed are the remaining technology challenges that might be resolved with further ground technology research, geared toward reducing technical risks associated with future space validation and science missions.
\end{abstract}

\section{Introduction}

$\mathrm{N}^{2}$ ASA's In-Space Propulsion Technology (ISPT) Program is investing in technologies that have the potential to revolutionize the robotic exploration of deep space. For robotic exploration and science missions, increased efficiencies of future propulsion systems are critical to reduce overall life-cycle costs and, in some cases, enable missions previously considered impossible. Continued reliance on conventional chemical propulsion alone will not enable the robust exploration of deep space - the maximum theoretical efficiencies have almost been reached and they are insufficient to meet needs for many ambitious science missions currently being considered. The ISPT Program is developing technologies from a Technology Readiness Level (TRL) of 3 through TRL 6.

Solar sail propulsion uses sunlight to propel vehicles through space by reflecting solar photons from a large, mirror-like sail made of a lightweight, reflective material. Because the Sun supplies the necessary propulsive energy, solar sails also require no onboard propellant, thus reducing payload mass. The NASA Science Mission Directorate Earth-Sun Systems Division's Draft Heliophysics Roadmap ${ }^{1}$ has identified a number of missions that can be enhanced by solar sails, as shown in Figure 1, Heliophysics Mission Roadmap. For example, the continuous photonic pressure provides propellantless thrust to hover indefinitely at points in space (e.g. Heliostorm/L1) or conduct orbital maneuver plane changes (e.g. Solar Polar Imager - SPI) much more efficiently than conventional chemical propulsion. Eventually, a solar sail might propel a space vehicle to tremendous speeds-theoretically much faster than any present-day propulsion system - to reach interstellar space and explore the heliopause (e.g. Inter Stellar Probe - ISP).

Solar Sail Propulsion (SSP) is one of ISPT's three high priority investment areas, with the objective of near term verification and development of solar sail system level technology through ground testing and the development of subsystems, operations tools and computational models. NASA's Science Mission Directorate (SMD) funded research based on the results of peer reviewed proposals submitted to Topics in the Research Opportunities in Space Science (ROSS) of NASA Research Announcements (NRA). Table 1 lists the major SSP solicitations that were conducted under two ROSS NRA's (referred to as Cycle 1 and Cycle 2) and several smaller tasks issued to various NASA Centers as Directed Tasks. The SMD intends that space science solicitations should be guided

\footnotetext{
* Systems Engineer, Instrument \& Payload Systems Department/EI61, Member AIAA

${ }^{\dagger}$ Solar Sail Technical Area Manager, In-Space Propulsion Project Office/VP51, Member AIAA
} 
Sacramento, CA

July 9-12, 2006

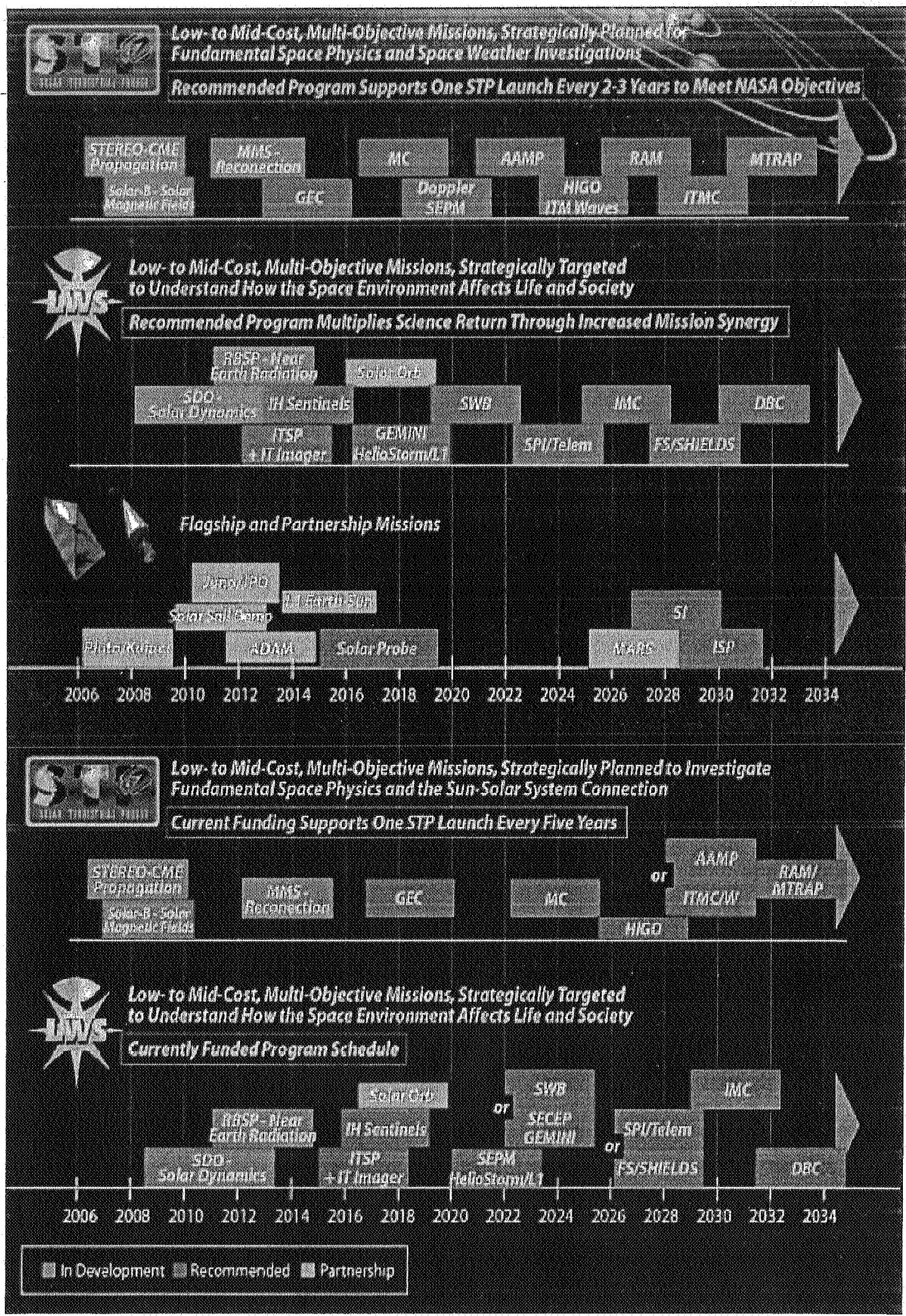

Figure 1: Heliophysics Mission Roadmap

2

American Institute of Aeronautics and Astronautics

This material is declared a work of the U.S. Government and is not subject to copyright protection in the United States 


\begin{tabular}{|c|c|c|}
\hline \multicolumn{3}{|l|}{ ROSS CYCLE 1 TASKS } \\
\hline Name & PI & Status \\
\hline $\begin{array}{c}\text { Scalable Solar Sail System }\left(S^{4}\right) \text { Ground } \\
\text { Demonstration }\end{array}$ & $\mathrm{AEC}$ & Completed \\
\hline $\begin{array}{l}\text { Bringing an Effective Solar Sail Subsystem to TRL } \\
6 \text { Ground Demonstration }\end{array}$ & L'Garde & Completed \\
\hline Solar Sail Spaceflight Simulation Software (S5) & JPL & Completed \\
\hline \multicolumn{3}{|l|}{ ROSS CYCLE 2 TASKS } \\
\hline Optical Diagnostics System for Solar Sails & NASA LaRC & $\begin{array}{l}\text { Phase } 1 \text { completed; } \\
\text { option not exercised }\end{array}$ \\
\hline $\begin{array}{l}\text { Advanced Computational Models and Software for } \\
\text { Design and Simulation of Solar Sails Including } \\
\text { Experimental Validation }\end{array}$ & NASA LaRC & $\begin{array}{l}\text { Phase } 1 \text { completed; } \\
\text { option not exercised }\end{array}$ \\
\hline $\begin{array}{l}\text { Development of a Low-Cost, Low-Mass, Low- } \\
\text { Volume, and Low-Power Attitude Determination } \\
\text { and Control System (L4-ADCS) and High- } \\
\text { Fidelity Computational Models of Solar Sail } \\
\text { Systems }\end{array}$ & $\begin{array}{l}\text { Arizona State } \\
\text { University }\end{array}$ & Completed \\
\hline $\begin{array}{l}\text { Laboratory Characterization of Candidate Solar Sail } \\
\text { Material }\end{array}$ & NASA MSFC & Completed \\
\hline $\begin{array}{l}\text { Advanced Manufacturing Technologies for Solar } \\
\text { Sails using Processes Developed Specifically for } \\
\text { Production of Ultra-thin Solar Sail Materials for } \\
\text { Near, Mid and Far Term Space Science Missions }\end{array}$ & SRS Tech & On going \\
\hline $\begin{array}{l}\text { Structural Analysis \& Synthesis Tools for Solar } \\
\text { Sails }\end{array}$ & JPL & $\begin{array}{c}\text { Phase } 1 \text { completed; } \\
\text { option not exercised }\end{array}$ \\
\hline \multicolumn{3}{|l|}{ DIRECTED TASKS } \\
\hline Smart Adaptive Structures & NASA MSFC & On going \\
\hline Sail Charging & NASA MSFC/JPL & Completed \\
\hline Long duration materials test & NASA MSFC & On going \\
\hline
\end{tabular}

Table 1. ROSS NRA and Directed Tasks

by input from the technology community. In the ISPT, and this is best achieved through the periodic convening of Technology Assessment Groups (TAGs). The first ISPT Solar Sail TAG was held over two days in January, $2002^{2}$. The interest represented at the TAG included the highest priority solar sail subsystems and components as well as the technical experts in photogrammetry, testing of gossamer structures and modeling. The TAG participants formed discussion groups to define what ground based testing and tools were needed in order to advance the solar sail Technology Readiness Level (TRL). Figure 2 is the Solar Sail technology development roadmap that was synthesized from the discussion group worksheets and has been used by the SSP office to develop all of the subsequent research solicitations. TAG's held in March, $2004^{3}$, and September, $2005^{4}$, further refined the roadmap with the recommendation of an additional ground demonstration of 40 meters to verify manufacturability and scalability of design, and provided an avenue for feedback from the PI's on the status of their work. The 2005 TAG was also significant in that two days were allocated for the Cycle 1 PI's to report the results of the manufacture and testing of two 20 meter Ground System Demonstrations prior to the TAG general meeting.

\section{ISTP Cycle 1 Solicitation}

\section{A. System Level Ground Demonstration}

The first of two SSP research elements in the ISTP Cycle 1 called for a prototype solar sail system for ground testing that would be used to validate design concepts for: sail manufacturing, packaging, launch to 


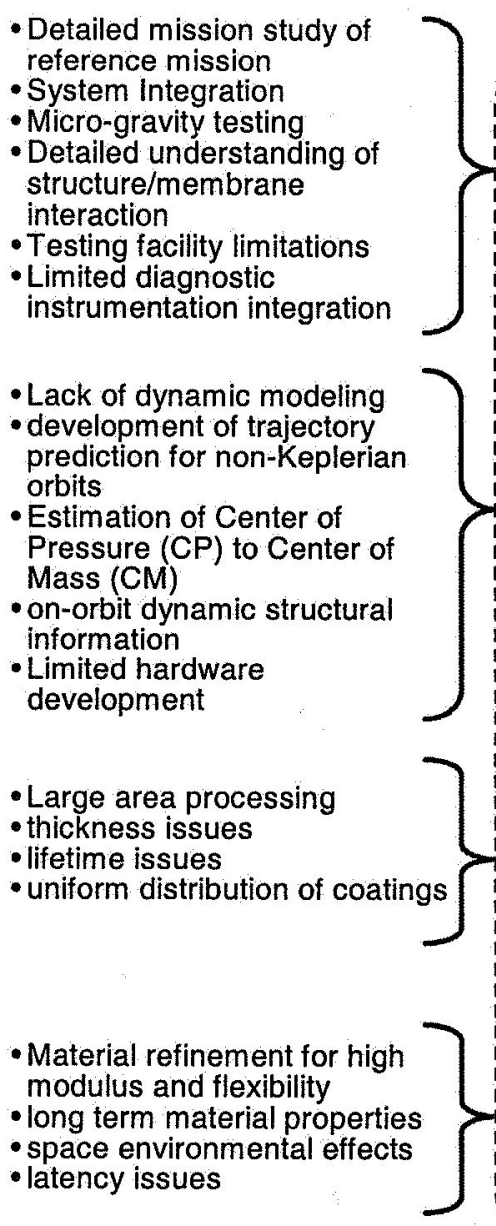

- latency issues

Technology Challenges
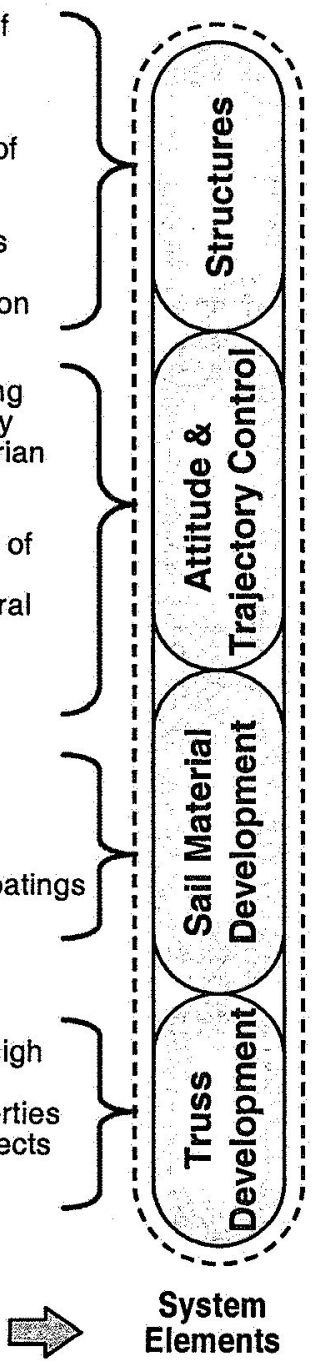

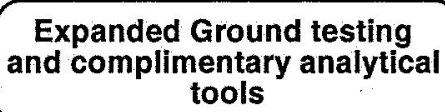

Preliminary system design and testing plan which satisfy eference mission requirement

Trade study of reference mission to determine optimal orbit and ACS methodology

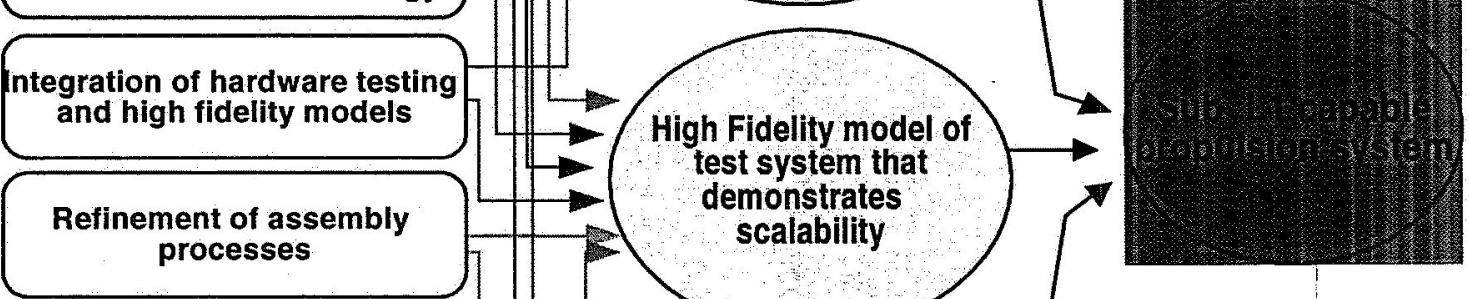

\section{Long duration effects testing}

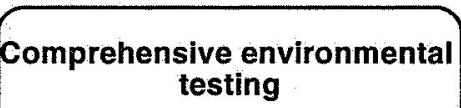
Scalable Ground Test monstration System
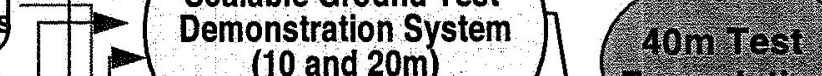

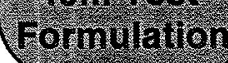

Further material development
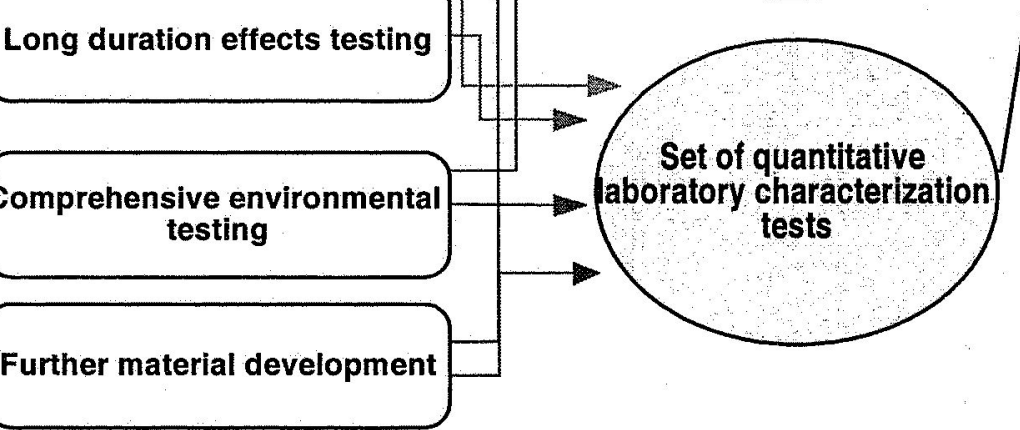

Technology

Development

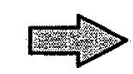

Near-term Product

Figure 2: Solar Sail TAG Roadmap

4

American Institute of Aeronautics and Astronautics 
Sacramento, CA

July 9-12, 2006

space and deployment; attitude control subsystem function; and to characterize the structural mechanics and dynamics of the deployed sail in a simulated space environment. The solicitation called for a square sail configuration consisting of a reflective sail membrane, a deployable sail support structure, an attitude control subsystem, and all hardware needed to stow the sail for launch. In addition this system was required to meet the characteristics given in Table 2, columns 1 and 2. A sub-L1 solar monitoring mission concept was also provided as a reference mission for guidance in design and scalability issues, and is summarized in Table 3.

SSP awarded ground demonstration contracts to two companies that had proposed two separate types of technologies in order to achieve the project objective. ABLE Engineering Company's (now ATK Space Systems) proposed work based on their prior New Millennium Program (NMP) ST-7 proposal, incorporating their rigid coilable boom, an articulating boom attitude control system (ACS) subsystem and partner SRS' CP1 sail membrane. L'Garde Inc. proposed work based on the experience they gained on a NMP ST 5 proposal and as the sail provider for Team Encounter, incorporating their inflatable and sub-Tg rigidizable boom, a control vane based ACS and Mylar for the sail membrane. The parallel testing and development of these two system level demonstrations that have varied technologies in the three major components removed the risk to this technology development if one provider encountered an unrecoverable failure. The system level ground demonstration work was divided into three phases. A six month concept refinement phase was completed in May, 2003. During this Phase, the two teams provided analysis of their system's performance when scaled to the Design Reference Mission and a preliminary test plan for the following two twelve-month phases. The twelve-month hardware development phase began in June, 2003. In this phase both teams built and tested components and subsystems, with ATK concentrating on a single 10meter quadrant and L'Garde developing a 10-meter square sail. The most comprehensive of these tests occurred in the middle of 2004 when the respective teams deployed their integrated subsystem in the LaRC 14-meter vacuum facility (ATK) and the 30-meter vacuum chamber at Glenn Research Center's Plum Brook Space Power Facility (L'Garde). Following a successful second phase the teams culminated their work in a twelve-month system verification phase. In this phase both teams built and tested fully integrated 20 -meter sail systems that included a launch packaging container, and operational ACS subsystems. In the middle of 2005, the respective teams tested their system in the Plum Brook Facility under a high vacuum and appropriate thermal environment, as well as subjecting their systems to launch vibration and ascent vent tests. Figures 3 and 4 show the 20-meter deployed systems at the Plum Brook Facility. Table 2, columns 3 and 4 summarizes the final metrics achieved by ATK and L'Garde with their 20-meter systems. Since these sails represent the largest systems that will be tested in a vacuum chamber on the ground, a significant effort was made to collect static and dynamic data on the sails and booms with approximately $400 \mathrm{~Gb}$ of data collected, primarily raw photogrammetry data. Technical descriptions of work being performed by $\mathrm{AEC}^{5,6,7,8}$ and $\mathrm{L}^{\prime} \mathrm{Garde} \mathrm{e}^{9,10,11}$ on the 20 -meter GSD can be found in the respective team's papers.

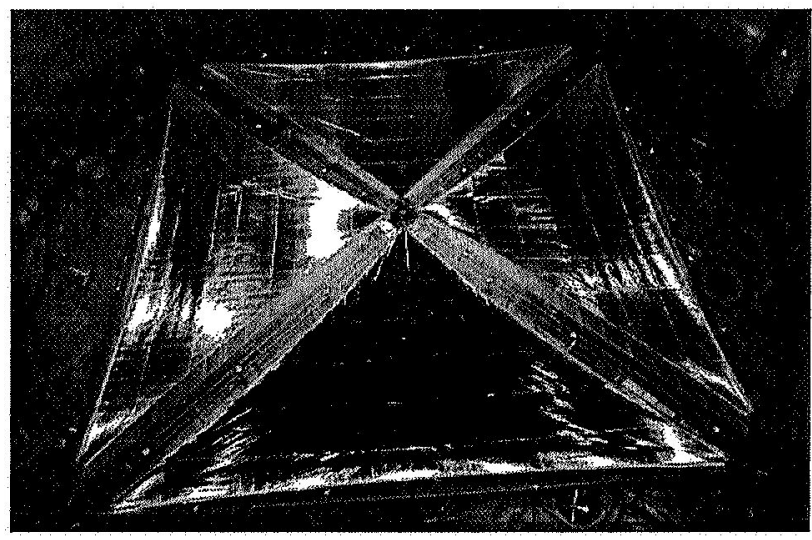

Figure 3. ATK 20 meter SGD

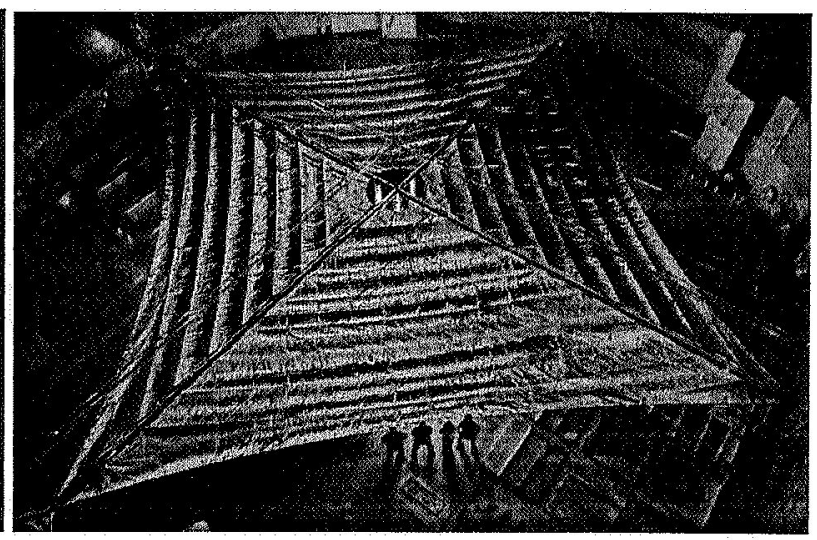

Figure 4. L'Garde 20 meter SGD 


\begin{tabular}{|c|c|c|c|}
\hline METRIC & RFP & ATK & - L'GARDE \\
\hline Dimensions: & $\begin{array}{ll}20 \text { meters } \times & 20 \\
\text { meters } & \text { or }\end{array}$ & $\begin{array}{l}\text { - 20-m system with flight like } \\
\text { central structure }\end{array}$ & $\begin{array}{l}\text { - } 19.5 \mathrm{~m} \text { due to Plumbrook } \\
\text { - } 1 \text { subscale TVCAD vane }\end{array}$ \\
\hline & greater & $\begin{array}{l}\text { - } 4 \text { sails scaled from } 80 \mathrm{~m} \\
\text { - Truncated } 80 \mathrm{~m} \text { masts } \\
\text { - Central structure scaled from } \\
40-\mathrm{m}\end{array}$ & $\begin{array}{l}\text { - Non-flight central structure } \\
\text { scaled for } 100 \mathrm{~m} \text { system } \\
\text { - Sails and mast truncated } \\
100 \mathrm{~m} \text { system }\end{array}$ \\
\hline $\begin{array}{l}\text { Sail Subsystem } \\
\text { Areal Density }\end{array}$ & $\begin{array}{l}<\quad 20 \mathrm{~g} / \mathrm{m}^{2} \\
\text { (scalability to } \\
12 \mathrm{~g} / \mathrm{m}^{2} \text { for } \\
104 \mathrm{~m} 2 \text { ) }\end{array}$ & $\begin{array}{l}112 \mathrm{~g} / \mathrm{m}^{2}-\text { includes } \\
\text { spacecraft bus structure, } \\
\text { ACS, power, instrument } \\
\text { boom } \\
\text { - scaled to } 11.3 \mathrm{~g} / \mathrm{m} 2 \text { for } 100 \mathrm{~m} \\
\text { design and no payload }\end{array}$ & $\begin{array}{l}30 \mathrm{~g} / \mathrm{m}^{2}-\text { includes ACS (4 } \\
\text { vanes calculated), central } \\
\text { structure dropped } \\
\text { - scaled to } 14.1 \mathrm{~g} / \mathrm{m}^{2} \text { with } 50 \mathrm{~kg} \\
\text { payload and } 41.4 \mathrm{~kg} \text { bus }\end{array}$ \\
\hline $\begin{array}{l}\text { Stowed } \\
\text { Volume }\end{array}$ & $\begin{array}{l}<0.5 \mathrm{~m}^{3} \\
\text { (scalability to } \\
1.5 \mathrm{~m}^{3} \text { for } 104 \\
\mathrm{~m}^{2} \text { ) }\end{array}$ & $\begin{array}{l}0.9 \mathrm{~m}^{3} \text { scaled to } 1.5 \mathrm{~m}^{3} \text { for } \\
100 \mathrm{~m} \text { design }\end{array}$ & $\begin{array}{l}2.14 \mathrm{~m}^{3} \text { scaled to } 1.04 \mathrm{~m}^{3} \text { for } \\
100 \mathrm{~m} \text { design }\end{array}$ \\
\hline $\begin{array}{l}\text { Thrust Vector } \\
\text { Turning Rate } \\
\text { about roll axis: }\end{array}$ & $>1.5 \% \mathrm{hr}$ & - $>35^{\circ}$ maneuver in 2 hrs & - $63 \%$ hour $(.0$ \\
\hline $\begin{array}{l}\text { Effective Sail } \\
\text { Reflectance }\end{array}$ & $>0.75$ & - $92 \%$ over solar spectrum & - 85.9 \\
\hline $\begin{array}{l}\text { Anti-sunward } \\
\text { Emissivity }\end{array}$ & $>0.30$ & - 0.30 for 3 micron film & - 0.40 \\
\hline $\begin{array}{l}\text { Membrane } \\
\text { Characteristics }\end{array}$ & $\begin{array}{l}\text { space-durable, } \\
\text { tear-resistant, } \\
\text { designed for } 1 \\
\text { year in the } \\
\text { near-GEO } \\
\text { environment }\end{array}$ & $\begin{array}{l}-2 \text { micron CP1 with } 1000 \mathrm{~A} \\
\text { of aluminum on front, bare } \\
\text { CP1 on back of sail. All } \\
\text { materials have space flight } \\
\text { heritage. }\end{array}$ & $\begin{array}{l}\text { - } 2 \text { micron Mylar with } 1000 \text { A } \\
\text { of aluminum on front and } \\
200 \mathrm{~A} \text { blackened chromium } \\
\text { on back }\end{array}$ \\
\hline $\begin{array}{l}\text { System } \\
\text { Flatness }\end{array}$ & $\begin{array}{l}\text { Effective for } \\
\text { Propulsion }\end{array}$ & $\begin{array}{l}\text { - 3-point quadrant support } \\
\text { with shear compliant } \\
\text { border to insure a flat sail, } \\
\text { with a proper stress level to } \\
\text { obtain local flatness }\end{array}$ & - Stripped net loss $\sim 2 \%$ \\
\hline ACS & $\begin{array}{l}\text { 3-axis, } \\
\text { minimize } \\
\text { propellant } \\
\text { usage }\end{array}$ & $\begin{array}{l}\text { - Sliding trim control mass on } \\
\text { truss and tip bars to } \\
\text { pinwheel quadrants for roll. } \\
\text { Micro PPT backup }\end{array}$ & $\begin{array}{l}\text { - Totally propellantless using } \\
\text { four tip vanes }\end{array}$ \\
\hline
\end{tabular}

Table 2. Cycle 1 System Level Ground Demonstration Reporting Metrics

\section{B. Solar Sail Integrated Software Tools}

The second of two SSP research elements in the ISTP Cycle 1 called for a set of integrated simulation tools to predict the trajectory, maneuvers, and propulsive performance of a solar sail during a representative flight profile. The solicitation encouraged that these tools should be able to be integrated into an optimal GNC subsystem on a future flight mission. In addition, the tools were required to be applicable to a solar sail mission of characteristics given in Table 3 and incorporate the following analytical models:

- Solar radiation pressure acting on the sail as a function of sail orientation and distance from the Sun. 
- Disturbance forces acting on the sail such as gravitational torques and thermal deformation of the support structure.

- Orbital mechanics

- Sail structural dynamics

- Attitude control system dynamics

- Navigational sensors

The Solar Sail Spaceflight Simulation Software (S5) incorporated a six month Phase 1 that was completed in September, 2003, with Phase 2 completed in July, 2004, and Phase 3 completed in February, 2006. At the end of Phase III, of the 173 requirements specified in the S5 Software Requirements Document, 66 were fully implemented and integrated into the S5 system and 50 were partially integrated into the system or fully implemented in a standalone code. See reference 12 for a discussion of the S5 software and recent validation efforts.

\begin{tabular}{|c|c|c|c|c|c|r|r|r|}
\hline $\begin{array}{r}\text { Launch } \\
\text { Mass (kg) }\end{array}$ & $\begin{array}{c}\text { Payload } \\
\text { Mass (kg) }\end{array}$ & $\begin{array}{c}\text { Payload } \\
\text { Power (W) }\end{array}$ & $\begin{array}{c}\text { Total } \\
\text { Power } \\
(\mathrm{W})\end{array}$ & $\begin{array}{c}\text { TM } \\
\text { Dish } \\
(\mathrm{m})\end{array}$ & $\begin{array}{r}\text { TM } \\
\text { Band }\end{array}$ & $\begin{array}{r}\text { TM } \\
\text { Rate } \\
(\mathrm{Kb} / \mathrm{s})\end{array}$ & $\begin{array}{r}\text { S/C } \\
\text { Dia (m) }\end{array}$ & $\begin{array}{r}\text { Launch } \\
\text { Vehicle }\end{array}$ \\
\hline 250 & 50 & 100 & 750 & 1.5 & $\mathrm{X}$ & 100 & $<2.3$ & $\begin{array}{r}\text { Delta } \\
2425-9.5\end{array}$ \\
\hline
\end{tabular}

Table 3. Design Reference Mission

\section{Cycle 2 Task}

\section{A. Optical Diagnostic System}

The overall objective for this task is the development of an Optical Diagnostic System (ODS) to TRL 6 for a solar sail. Possible requirements for the ODS included observation of the sail deployment and monitoring of the health and integrity of the sail during and after deployment. After solar sail deployment, the ODS would be available to provide shape and vibration measurements adequate to infer the stress state of the solar sail by aid of computational structural models which could then feed real time into a closed loop spacecraft guidance and control system. The initial six-month base period included concept development preceded by definition of the goals, priorities, and requirements for the ODS ${ }^{13}$. It was determined that continuous real-time integration with the guidance system was not necessary due to the quasi-steady-state nature of solar sail operations. In addition, studies by Zeiders ${ }^{14}$ and Ewing ${ }^{15}$, showed the relative insensitivity of the thrust vector magnitude and direction to sail billow. The conceptual design process identified a number of significant challenges to on-orbit photogrammetry including significant weight, power, and data requirements for instruments and support structures for camera clusters, achieving sufficient image contrast, integrating targets into the sail membrane, and considerable software development needs. The concept development activities were conducted in parallel with the development of the ground test capability for the solar sail demonstrator hardware. A developmental test of a L'Garde inflatable boom in a thermal vacuum chamber at Goddard Space Flight Center, as well as tests on smaller sail quadrants ${ }^{16}$, provided an opportunity to familiarize researchers with cameras, analytical tools, and test operations. Building on this experience and adding capabilities for dynamic excitation and laser vibrometry, imaging, and a "truth" instrument, the ATK 10-meter demonstrator testing was performed in the 16-meter vacuum chamber at LaRC. These activities formed the foundation for the test methods and instrumentation employed in the final 20-meter demonstrations tests. An exceptional team of photogrammetry experts from LaRC, working in conjunction with the contractor test teams, were successful in acquiring both static and dynamic deflection data in a number of various thermal and vacuum conditions and system configurations despite tremendous difficulties that arose. For example, condensate "rain" fell on the test article as the huge Plum Brook chamber was pumped down, causing boom tip positions to change so much that complex, remotely operated, adjustable instrument platforms had to be devised. A tremendous volume of data was required to provide high resolution measurements over 400 square meters of area and data collection was made difficult by the clean aluminum walls and floor of the chamber which provide little natural contrast to the aluminized sails. Finally, the cost of operations in such a large chamber is not inconsiderable. The teams were constantly under the gun to debug problems, acquire data, and assess data quality quickly with limited hands on the equipment and only a few pump-downs allowed. The difficulty of photogrammetry was not insurmountable, but it 
Sacramento, CA

July $9-12,2006$

did indicate the challenges identified in the conceptual design phase were real. Combined with a better understanding of the lack of a need for on-orbit photogrammetry, the further development of a flight system was not pursued.

\section{B. Advanced Computational Methods}

The TAG had expressed concern that conventional finite element models might be inadequate to evaluate solar sails. Therefore, a three pronged attack on the structural design issue was pursued. The first attack relied on the prime contractors to apply standard practices using the existing state of the art. As part of the Ground System Demonstrations, Finite Element Models (FEAs) were created by LaRC, ATK and L'Garde of the 10-meter systems using both COTS and custom software. These models didn't always converge and were computationally intensive, but no more so than is experienced in typical spacecraft design. The purpose of this task was to create methods/algorithms/techniques that improved the conventional FEA of the membranes, booms, and other subsystems. Several methods were identified, but the option phases to complete and validate them were not funded due to the success of the prime contractors in modeling the 20-meter systems with conventional techniques, thus lowering the priority of this task below the level of the available funding.

\section{Structural Analysis \& Synthesis Tools}

The third prong in the attack on the structural analysis issue involved the ground-up development of unconventional modeling techniques. Techniques considered included Direct Transfer Function Modeling (DTFM) and Parameter Variation Processing (PVP). The overall objectives for this task were completion of DTFM modeling/analysis methods for long booms, completion of capability to evaluate effects of imperfections, completion of PVP method for analyzing wrinkled membranes, and completion of testanalysis correlation by using existing test data. As in the above task, this effort was terminated prior to completion due to success using conventional modeling methods with the 20 -meter systems and a lack of funding.

\section{Lightweight Attitude Control System}

The objectives of this two -year project are: (i) to design, integrate, and test a sail attitude control system (SACS) employing a two-axis gimbaled control boom, and also (ii) to develop a high-fidelity, multi-flexible body model of ATK's solar sail for the purpose of validating a thrust vector control (TVC) concept employing a two-axis gimbaled control boom. One of the major findings from this study was that the two axis gimbaled control boom was not a mass efficient method of controlling a sail sail ${ }^{17}$. A more efficient method was derived based on an offset mass moved along the booms by a clothesline-like apparatus to control pitch and yaw and rotating stabilizer bars at the sail tips to pinwheel the sail quadrants for roll control. This finding led to a major redesign of the ATK 20-meter hardware to accommodate the new TVC concept. An attitude determination and control block diagram was derived to present the application/integration of the inertial stellar compass with a range of ACS options from $\mathrm{cp} / \mathrm{cm}$ offset to pulsed plasma microthrusters ${ }^{18}$. Although $95 \%$ of the work is complete ${ }^{19}$, the contract is currently open to enable further developments from other ASU research efforts to be incorporated.

\section{E. Characterization SS Material}

The purpose of this task was to conduct laboratory characterization of several candidate solar sail materials. The space radiation and micrometeoroid environments for 1.0 (Heliostorm) and 0.5 (SPI) astronomical units missions were defined and candidate materials were tested against these radiation and meteoroid environments. Through a series of learning tests, the sample hold down designs was optimized and a flexure test developed. Several samples of the SRS and L'Garde membrane materials were tested by subjecting them to gigarad levels of radiation - in simulations of long duration solar wind mission types ${ }^{20}$. While some of the samples showed significant levels of degradation in mechanical strength, solar sail loading is so low, very little strength is needed.

\section{F. Advanced Manufacturing Technologies for Solar Sails}

The purpose of this task was to investigate and develop an integrated approach to ultra-thin film solar sail manufacturing. The focus was on improving coating processes and technologies; developing sail seaming technologies for large monolithic sails; providing an integrated approach to membrane coating, acceptance, assembly and integration; and integrating future improvements (such as electrospun nanofibers for ripstop enhancement without added mass and the addition of carbon black nanotubes to the sail backside to increase emissivity $)^{21}$ into the process. The final results of this two-year effort are the development of a scroll coating system, 
Sacramento, CA

July $9-12,2006$

the development of coating capabilities of less than 2.5 microns, and the development of a membrane seaming system able to form monolithic sails with coatings at least as thin as 2.5 microns.

\section{Directed Tasks}

\section{A. Smart Adaptive Structures}

In order to mature the TRL of solar sail propulsion, advancements must be made in the pointing and dynamical control of these large space structures. This tasks' objective was to develop and verify structural analytical models, develop structural scaling laws and develop adaptive control laws for solar sails to be verified on a $>30$-meter vertically supported boom. In the summer of 2006 , a closed loop boom controller will be demonstrated.

\section{B. Charging in Space Environment}

Due to two extreme characteristics of future Solar Sail missions, the large surface area of the Sail and the long duration of potential missions, typical spacecraft charging issues will be exacerbated. The purpose of this task was to characterize charged particle environments for analyzing solar sail charging in the solar wind and at geostationary orbit and to model surface and internal electric fields and potentials for solar sails using existing spacecraft charging models. Solar sail materials were tested in simulated charging environments to determine permeability and charge retention properties. The task was completed March 1,2006. A significant finding was that there will be very little charging of the sail surfaces, $\sim 10$ volts as a worst case in sunlight. The study found that problems arise if the sail material backing is non-conductive or electrically decoupled from the front surface. In that case, the shadowed back surface can reach potentials of -30 to -40 volts relative to the space plasma in the solar wind - on the order of arcing onset potentials. The solution is to make sure the sail material is conductive front to back and end to end if the sail is to be in geosynchronous orbit or in the auroral zone and be very careful with electrically isolated objects in the shadow of the sail. ${ }^{22}$

\section{Long Term Space Environmental Effects}

Critical to the development of Solar Sails is an investigation of space environmental effects on these large thin film materials and the edge support technologies. This task was related to the "Characterization SS Material" task above. The above task used accelerated dose levels over a shorter period of time to simulate the total dose of radiation received by a material for many years. The purpose of this task is to provide critical thermal, optical, mechanical, and surface data on large sails taking into account edge stresses and edge support technologies that can only be characterized using large size sails but not at accelerated levels. These resulting test data could be used to validate the accelerated dose test methodology regarding the durability of candidate sail material (embrittlement, optical, mechanical, surface, and thermal properties). This task was recommended by 2004 TAG.

\section{SRS Solar Sail Propulsion Evaluation Tool}

This sixteen-week study provides a better understanding of the impacts of non-ideal sail characteristics to support further solar sail development. This study is divided into three tasks. Task 1 is Integrated Optical Design Analysis (IODA) Software Modification to support solar sail propulsion analysis. The objective of the sail analysis model is to provide a detailed calculation of the thrust vector magnitude, direction, and center of pressure based on the predicted shape of the sail and the sail optical properties including reflectivity, emissivity, and specularity. The program will also calculate the torques applied to the vehicle using the thrust vector, center of pressure, and vehicle center of mass. Task 2 is for the development of models to characterize the total momentum transfer imparted to a sail element (including the contributions from thermal emissions and diffuse reflections). Task 3 is for software testing. This is to include at least one FEM to be used for testing the software, demonstration of the software using any additional NASTRAN or ALGOR FEM models provided, and delivery of a Beta test version of the modeling software for evaluation by government personnel.

\section{Other Tasks}

A number of other proposed tasks were submitted as directed task requests, solicited in later NRAs, and recommended by the TAGs. They were not funded for various reasons, but mostly as a consequence of prioritization of the available budget. These included a combined effects material test in which MSFC irradiated samples would be sent to Glenn Research Center and exposed to the solar simulator thermal vacuum chamber environments. 


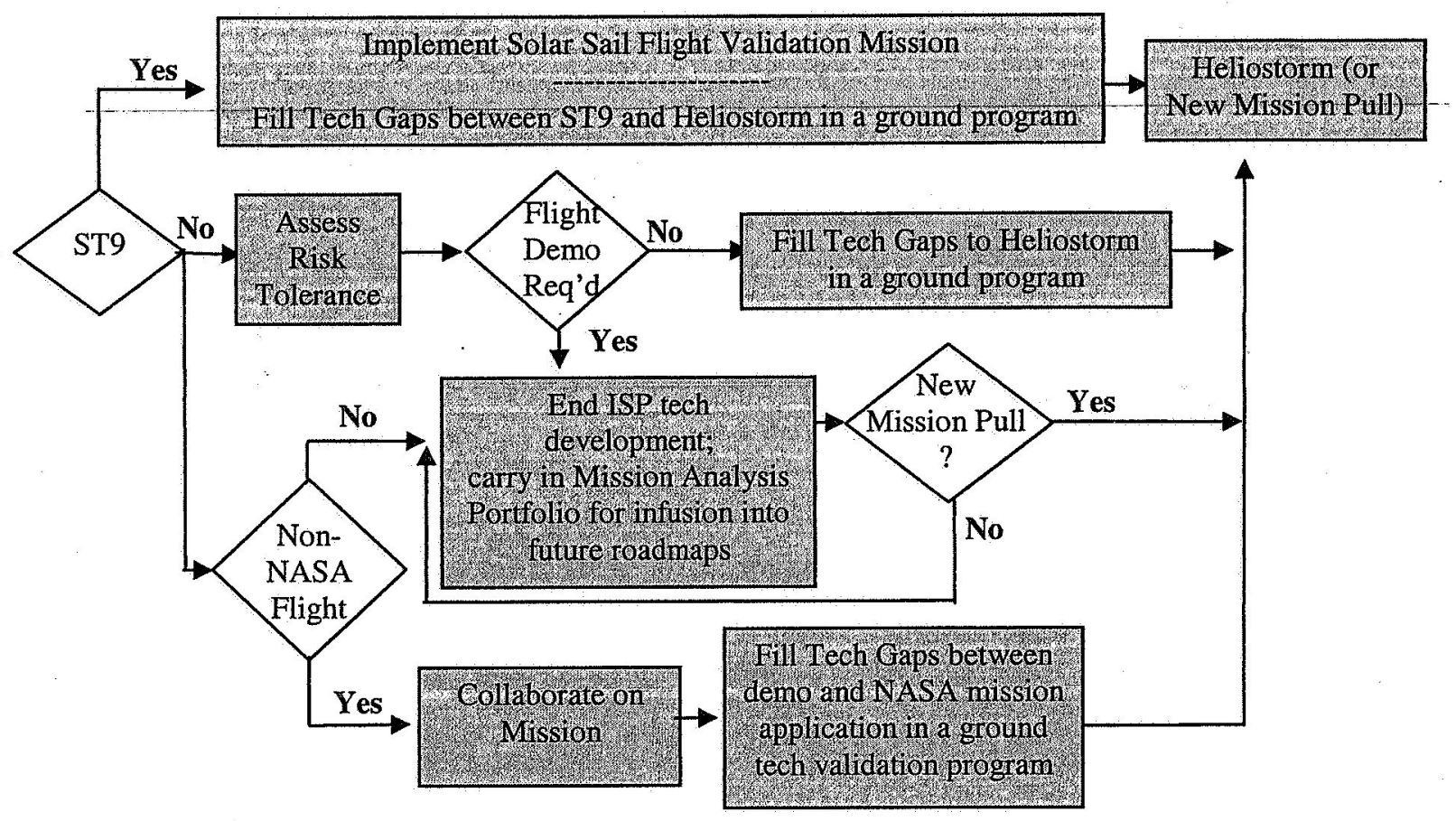

Figure 5. Solar Sail Decision Tree

Another task would create and organize a data base of known optical property data. Several interesting proposals were selected for direct measurement of thrust in a ground experiment.

\section{Future Directions}

The SSP Project approach of providing near term verification of solar sails through the development of system level technology using ground testing and the development of subsystems, operations tools and computational models has begun building a technological foundation that can be readily used by future programs (e.g., New Millennium Program) in their pursuit of providing space validation of this technology. As shown in Figure 5, the InSpace Propulsion Technology Program has developed a decision tree that lays out several potential paths to continue solar sail technology development based on the upcoming ST9 decision in late 2006. In so doing, this work will bring the technology to a readiness level such that it will minimize the exposure to risk of future flight programs.

\section{Acknowledgments}

The work described in this paper was funded in whole or in part by the In-Space Propulsion Technology Program, which is managed by NASA's Science Mission Directorate in Washington, D.C., and implemented by the In-Space Propulsion Technology Project at Marshall Space Flight Center in Huntsville, AL. The program objective is to develop in-space propulsion technologies that can enable or benefit near and mid-term NASA space science missions by significantly reducing cost, mass or travel times. 


\section{References}

${ }^{1}$ NASA Science Mission Directorate Draft Heliophysics Roadmap, April, 10, 2006, http://sec.gsfc.nasa.gov/HeliophysicsRoadmap4106.pdf

${ }^{-2}$ G. Garbe, 2002 Solar Sail Technical Assessment Group Report, NASA, 2002.

${ }^{3}$ C. Adams, 2004 Solar Sail Technical Assessment Group Report, NASA SSP-04-105, 2004

${ }^{4}$ R. Young, 2005 Solar Sail Technical Assessment Group Report, NASA SSP-05-106, 2005

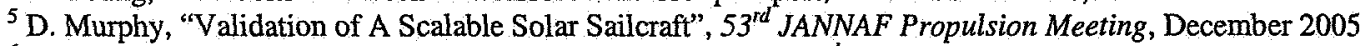

${ }^{6} \mathrm{~J}$. Gaspar et al., "Testing Of A 20-Meter Solar Sail System", $53^{\text {rd }}$ JANNAF Propulsion Meeting, December 2005

${ }^{7}$ B. Taleghani et al, " 20 Meter Solar Sail Analysis And Correlation", $53^{\text {rd }}$ JANNAF Propulsion Meeting, December 2005

${ }^{8}$ G. Laue, D. case, J. Moore, "Fabrication and Deployment Testing of Solar Sail Quadrants for a 20-meter Solar Sail Ground Test System Demonstration", 41st AIAA Joint Propulsion Conference, July 2005, AIAA 2005-3930

9 D. Lichodziejewski et al., "Vacuum Deployment and Testing of a $20 \mathrm{~m}$ Solar Sail System", 47th AIAA/ASME/ASCE/AHS/ASC Structures, Structural Dynamics, and Materials Conference, May 2006, AIAA 2006-1705

${ }^{10} \mathrm{D}$. Sleight et al., "Structural Analysis and Test Comparison of a 20-Meter Inflation-Deployed Solar Sail", 47th AIAAAASME/ASCE/AHS/ASC Structures, Structural Dynamics, and Materials Conference, May 2006, AIAA 2006-1706

${ }^{11}$ T. Mann et al., "Ground Testing A 20-Meter Inflation Deployed Solar Sail", 47th AIAA/ASME/ASCE/AHS/ASC Structures, Structural Dynamics, and Materials Conference, May 2006, AIAA 2006-1707

${ }^{12}$ J. Ellis et al., "A Solar Sail Integrated Simulation Toolkit", Proc. AAS/AISS Spaceflight Mechanics, Maui, HI, Feb., 2004, AAS 04-283

${ }^{13}$ R. Paippa et al., "Optical Diagnostic System for Solar Sails: Phase 1 Final Report”, NASA/TM-2004-213511, Dec. 2004

${ }^{14}$ G. Zeiders, "Design Rules and Scaling for Solar Sails", 4lst AIAA Joint Propulsion Conference, July 2005, AIAA 20054553

${ }^{15}$ A. Ewing, "Solar Sail Propulsion Sensitivity to Membrane Shape and Optical Properties Using the Solar Vectoring Evaluation Tool (SVET)", $53^{\text {rd }}$ JANNAF Propulsion Meeting, December 2005

${ }^{16}$ J. Black and R. Pappa, "Photogrammetry and Videogrammetry Methods for Solar Sails and Other Gossamer Structures", 45th AIAA/ASME/ASCE/AHS/ASC Structures, Structural Dynamics and Materials Conference, April 2004, AIAA 2004-1662

${ }^{17}$ D. Murphy and B. Wie, "Robust Thrust Control Authority for A Scalable Sailcraft", Proc. AAS/AISS Spaceflight Mechanics, Feb. 2004, AAS 04-285

${ }^{18}$ S. Thomas, M. Paluszek, B. Wie, D. Murphy, "AOCS Performance and Stability Validation for a 160-m Solar Sail with Control-Structure Interactions", 4 1st AIAA Joint Propulsion Conference, July 2005, AIAA 2005-3926

${ }^{19}$ Wie, B., "Thrust Vector Control Design for Solar Sail Spacecraft", ALAA Guidance, Navigation, and Control Conference, August 2005, AIAA 2005-6086

${ }^{20}$ D. Edwards, et al., "Characterization of Candidate Solar Sail Material Exposed to Space Environmental Effects", 42nd ALAA Aerospace Sciences Meeting and Exhibit, Jan. 2004, AIAA 2004-1085

${ }^{21}$ C. Talley, W. Clayton, P. Gierow, J. McGee, J. Moore, "Advanced Membrane Materials for Improved Solar Sail Capabilities", 43rd ALAA/ASME/ASCE/AHS/ASC Structures, Structural Dynamics, and Materials Conference: 3rd AIAA Gossamer Spacecraft Forum, April 2002, AIAA 2002-1561

${ }^{22}$ H. Garrett and J. Minow, "Charged Particle Effects on Solar Sails Final Report”, NASA TM (to be published) 
M09-0148-Presentation

Rapid Development Propulsion for NASA Inner Solar System Science Missions

$\because$

In Space Propulsion Technology Project NASA Marshall Space Flight Center. Roy Joung 4t Jwily $9-12,2006$
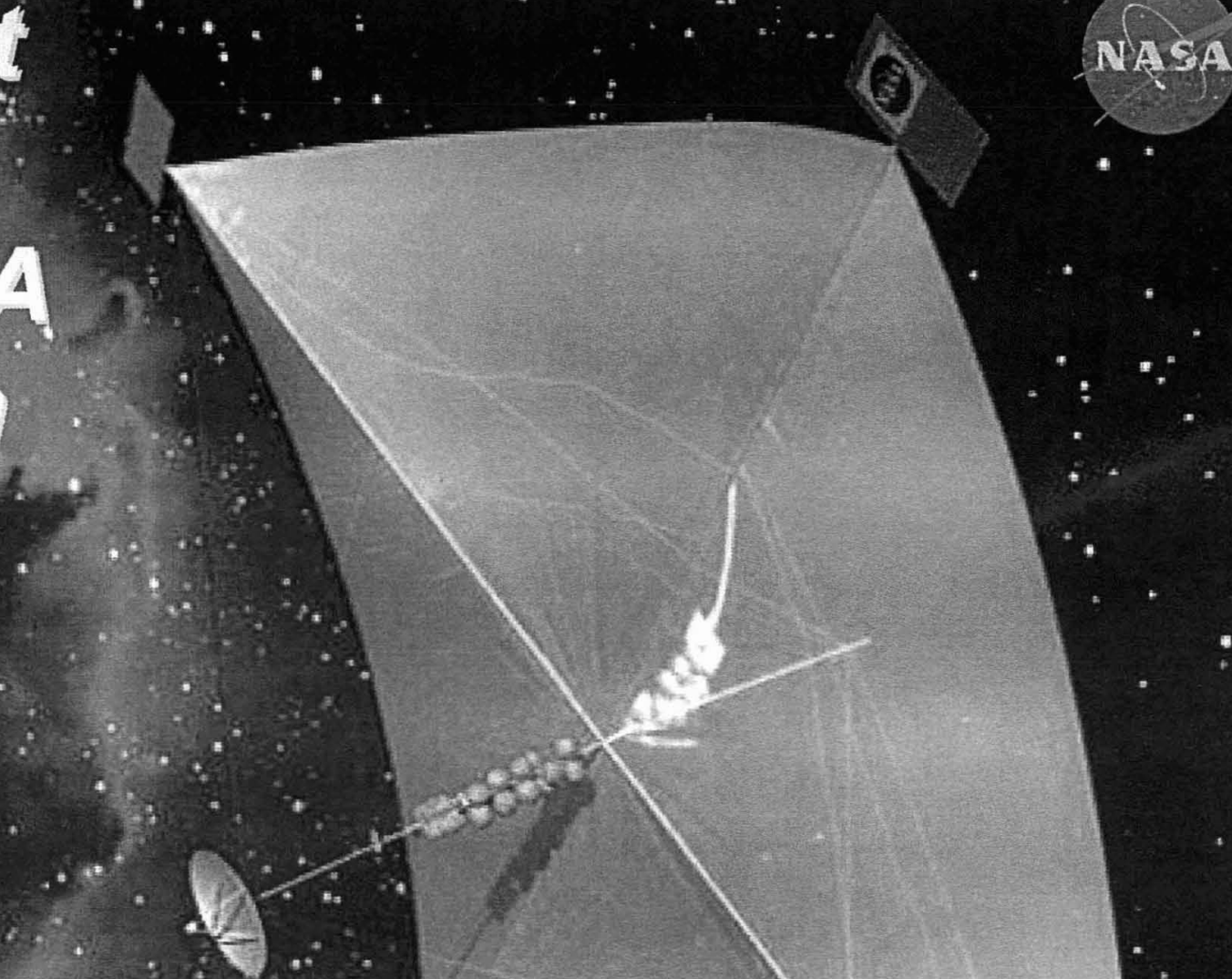


\section{Science Mission Technology Infusion}

\begin{tabular}{|l|l|l|l|l|l|l|l|l|l|l|l|l|l|l|l|l|l|l|l|l|l|l|l|l|l|}
\hline 05 & 06 & 07 & 08 & 09 & 10 & 11 & 12 & 13 & 14 & 15 & 16 & 17 & 18 & 19 & 20 & 21 & 22 & 23 & 24 & 25 & 26 & 27 & 28 & 29 & 30 \\
\hline
\end{tabular}

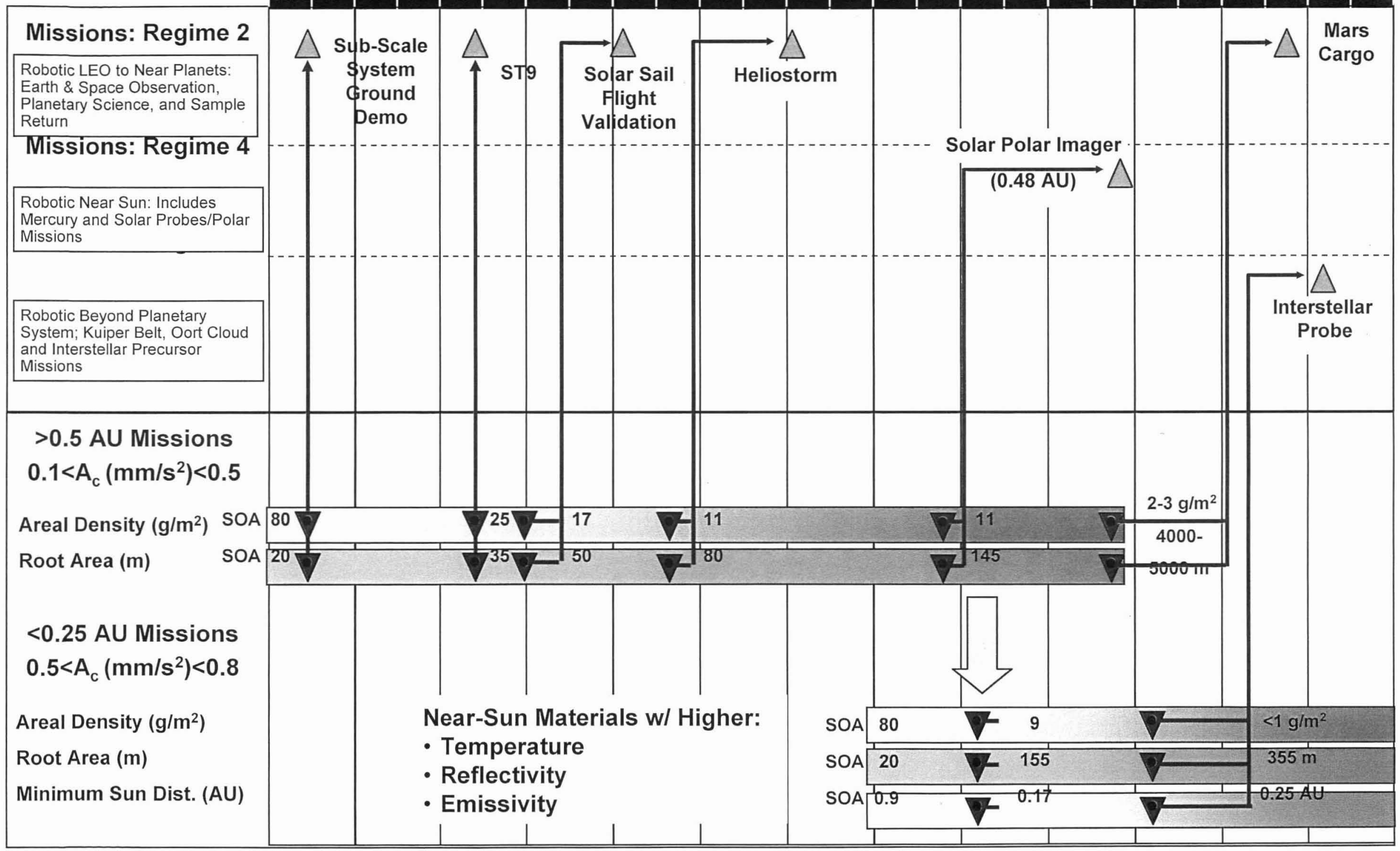




\section{TAG Assessment}

- Detailed mission study of reference mission

- System Integration

- Micro-gravity testing

- Detailed understanding of

structure/membrane

interaction

- Testing facility limitations

- Limited diagnostic

instrumentation

integration

- Lack of dynamic modeling

- Development of trajectory

prediction for non-

Keplerian orbits

- Estimation of Center of

Pressure (CP) to Center of

Mass (CM)

- On-orbit dynamic

structural information

- Limited hardware

development

- Large area processing

- Thickness issues

- Lifetime issues

- Uniform distribution of

coatings

- Material refinement for high modulus and flexibility

- Long term material

properties

- Space environmental

effects

- Latency issues

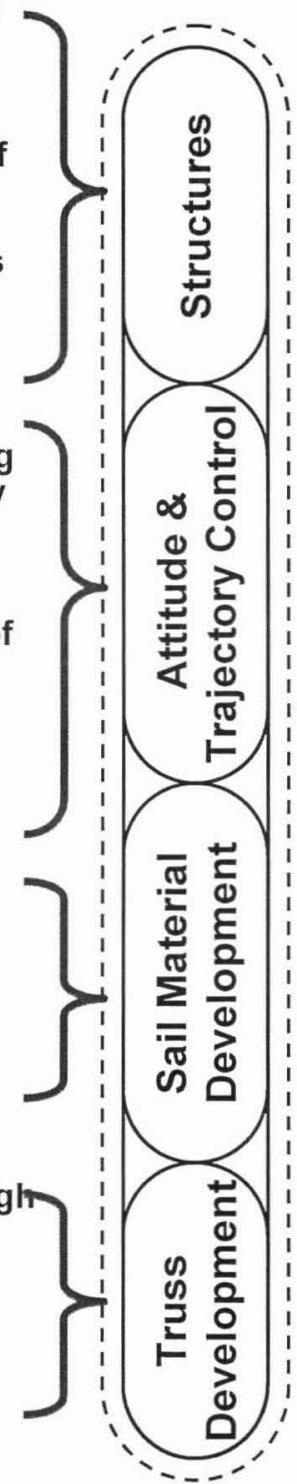

Technology

Challenges
System

Elements

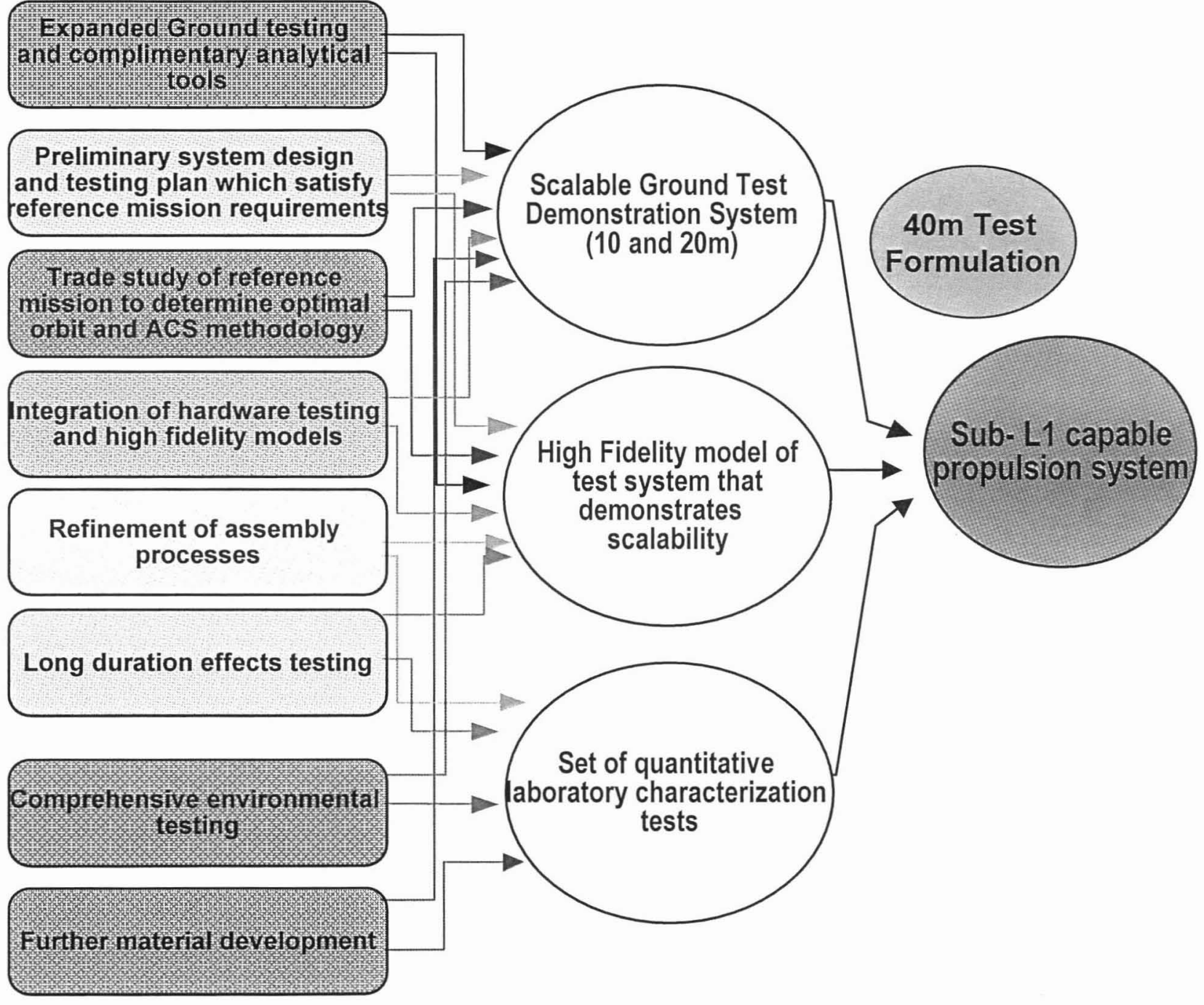

Technology Development
Near-term Product 


\section{Solar Sail Technology Roadmap}

\begin{tabular}{|lllllllllllllllll|}
\hline FY03 & FY04 & FY05 & FY06 & FY07 & FY08 & FY09 & FY10 & FY11 & FY12 & FY13 & FY14 & FY15 & FY16 \\
\hline
\end{tabular}

Future ROSES Solicitations

ST9

Cycle 1 Tasks

$>$ L'Garde

$>$ ATK

> S5 Trajectory

$\varangle \quad$ Cycle 2 Tasks

兄 $>$ ODS

$\checkmark$ AQSUIPSS ACS

$>$ MSFC Material testing

$>$ Ad. Comp. Methods

; Struct. Anal Tool

Advanced Sail Man.

FY06 Directed Tasks

$>$ Smart Adap. Struct

S Sail Charging

- Long duration materials test

- Combined Space Environ. Effects

> SS Optical Prop.

Cycle 4 Tasks

= Integrated Mission Study

2 Mission Ops, GN\&C

$\varangle \quad>$ Manufacturing Study

$\frac{x}{z} \quad>$ Thermal Analysis

$>$ Deployment Analysis

> Struct. Failures \& Test Anom.

Cycle 5 Tasks

2 High Fidelity Ground Demo
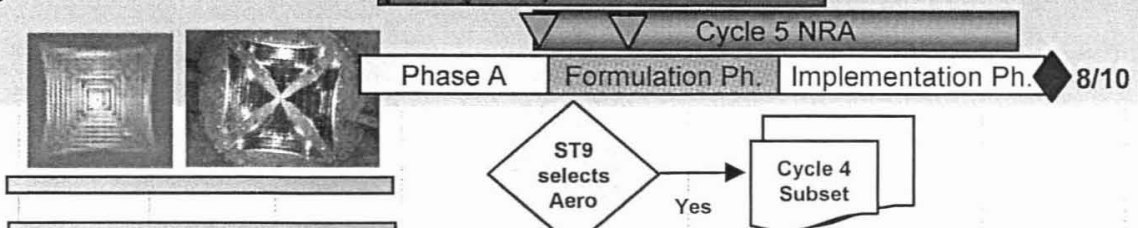

SS Flight Validation Heliostorm Mission 


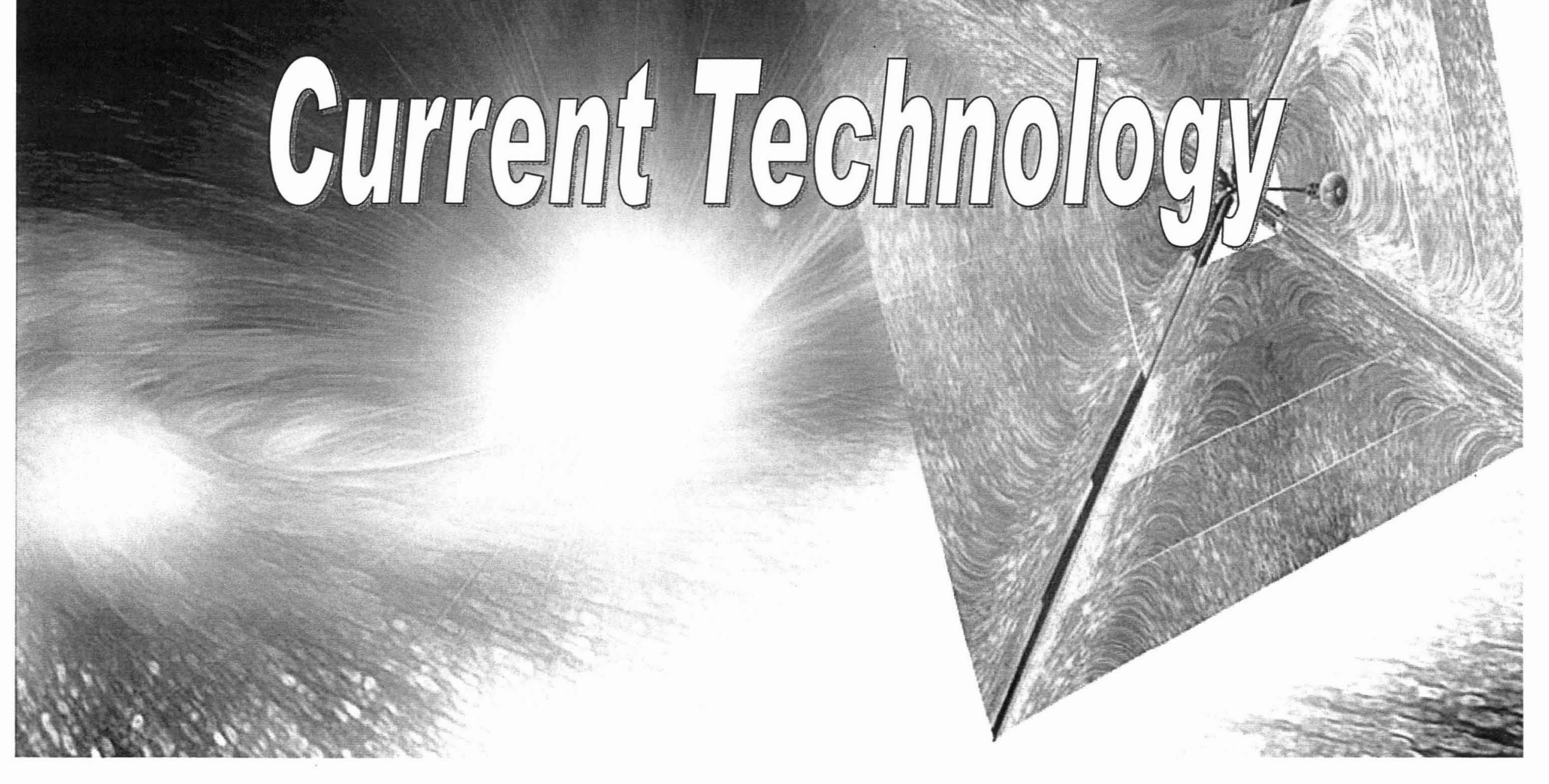

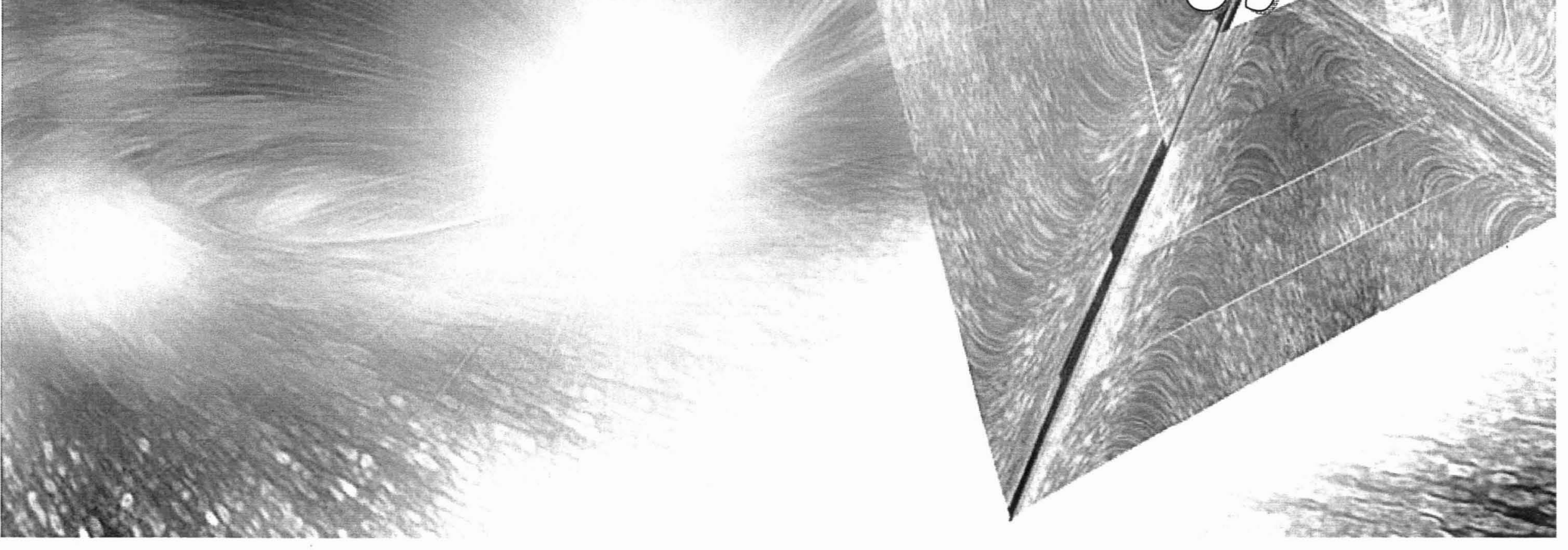




\section{Solar Sail Propulsion Technology Status}
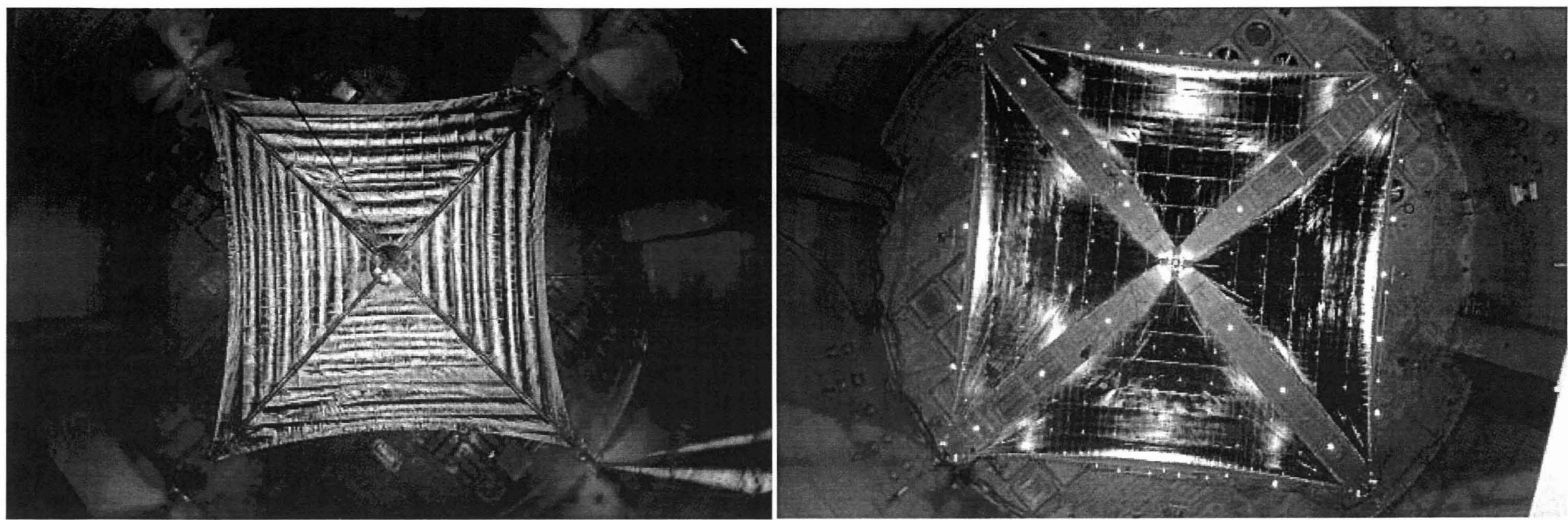

- Technology Area Status:

- Two parallel awards to design, fabricate, and test competing sail concepts for system level ground demonstration:

- $10 \mathrm{~m}$ system ground demonstrators were developed and tested in 2004.

- $20 \mathrm{~m}$ system ground demonstrators designed, fabricated, and tested under thermal vacuum conditions in 2005.

- Multiple awards to develop and test high-fidelity computational models, tools, and diagnostics.

- Multiple awards for materials evaluation, optical properties, long-term environmental effects, charging issues, smart adaptive structures. 


\section{ATK Task Summary}

PI: David Murphy, ATK Space Systems

- Proposal Team:

- ATK (Goleta, CA) systems engineering \& coilable booms

- SRS Technologies (Huntsville, AL): Sail manufacture \& assembly

- LaRC (Hampton, VA) Sail Modeling \& Testing

- MSFC (Huntsville, AL) Materials Testing

$\checkmark$ Overall Strategy

- Leverages ST 7 Phase A Design

- Improve performance with Ultra-Light Graphite Coilable booms

- Synergy with SailMast Testbed selected to fly on ST8

- Sail membrane, AL coated 2-4 $\mu$ m CP1, compliant border, 3 point attach

- Thrust Vector Control uses sliding masses along boom with spreader bars and micro-PPT at mast tip
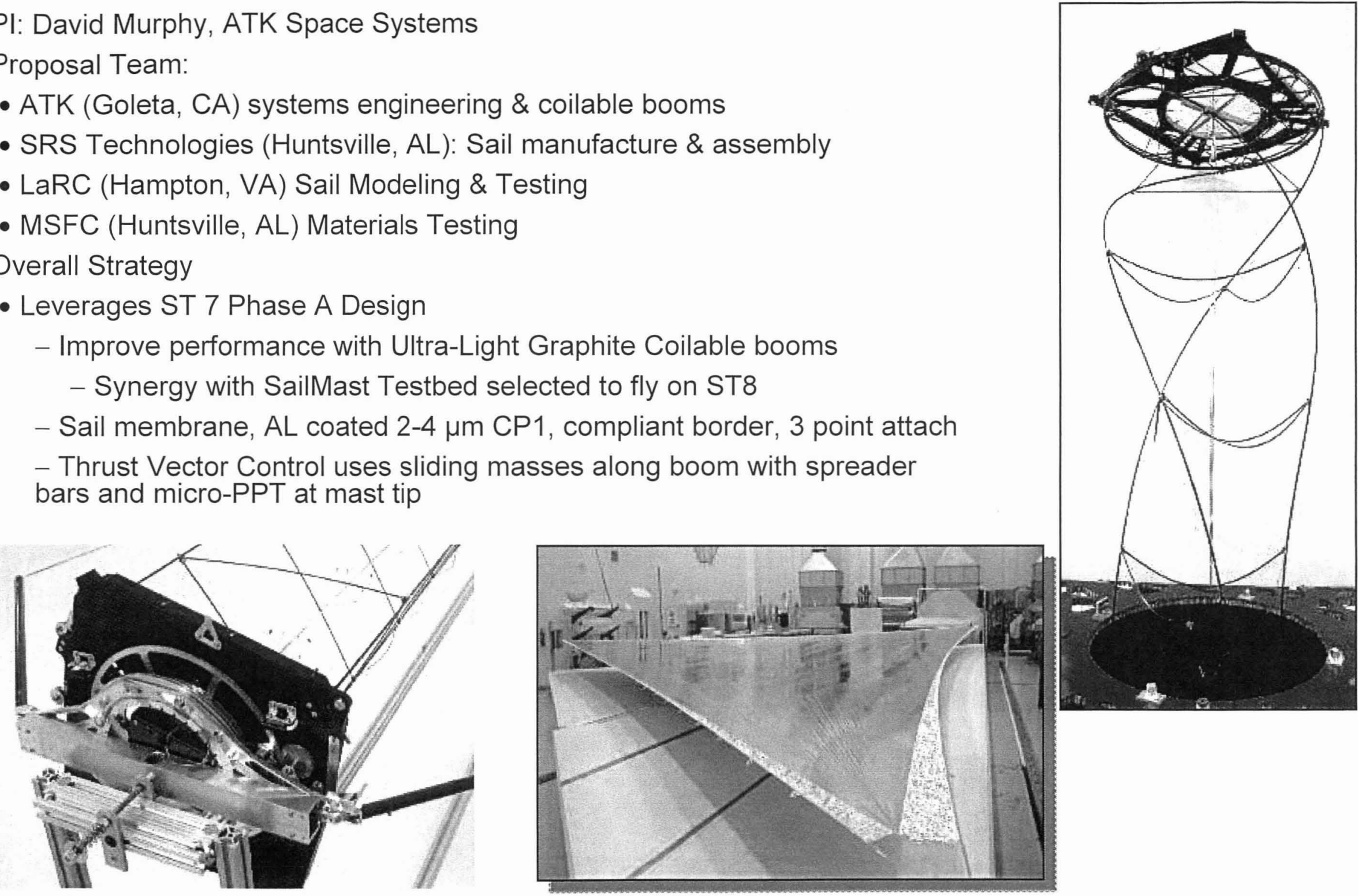


\section{CoilAble Mast Heritage}

- Able Engineering Company Established in 1975 (now ATK Space Systems)

- 30 CoilAble systems have been flown to date

- A phenomenal Stiffness to Weight ratio, High Dimensional Stability, Robust deployment, and Compact Stowage

- Recent flight mast designs

- Mars Pathfinder (1999) 1-meter boom: $130 \mathrm{~g} / \mathrm{m}$

- IMAGE spacecraft (2000) 10-meter booms: $93 \mathrm{~g} / \mathrm{m}$

- $100 \%$ Product Success Rate With No On-Orbit Failures

$\mathrm{LACE}$

ISP

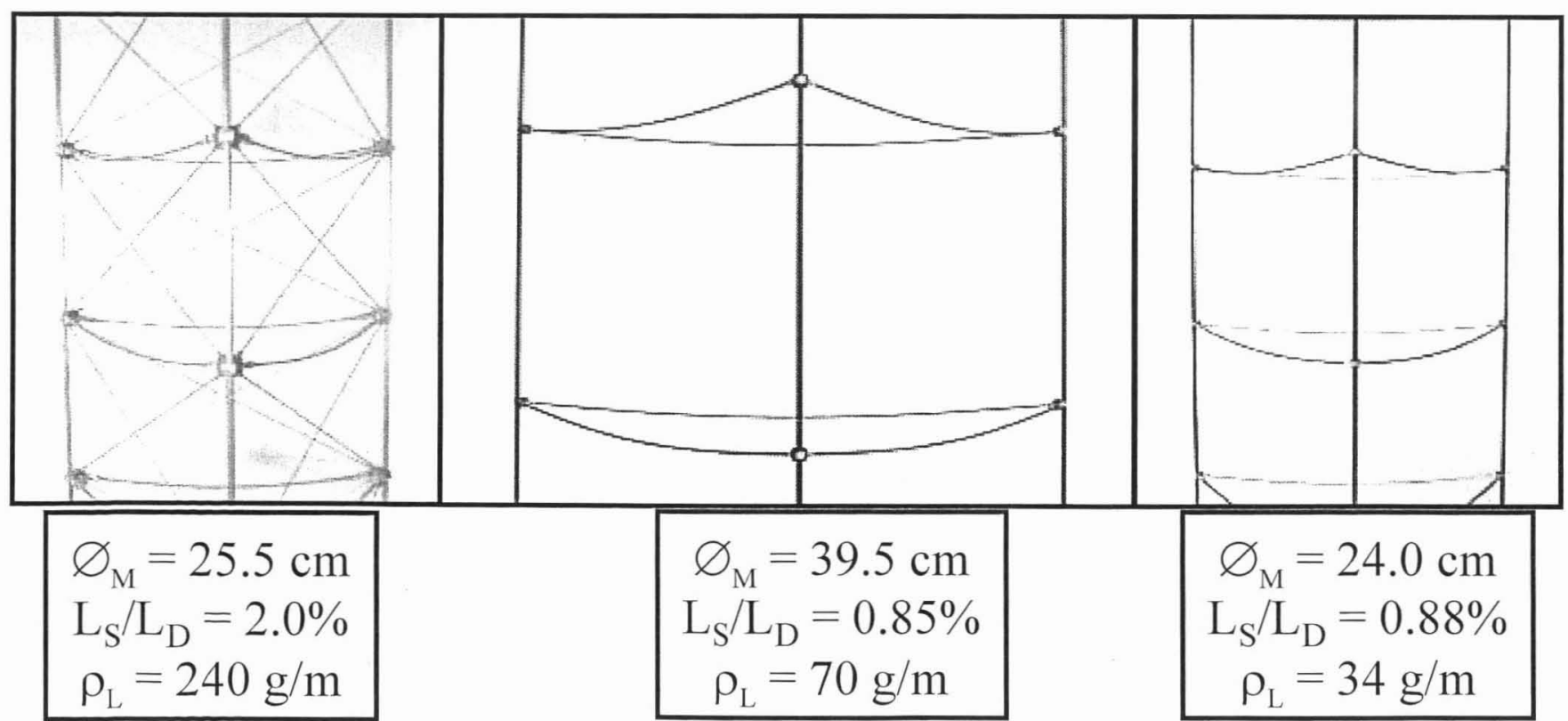

ST8

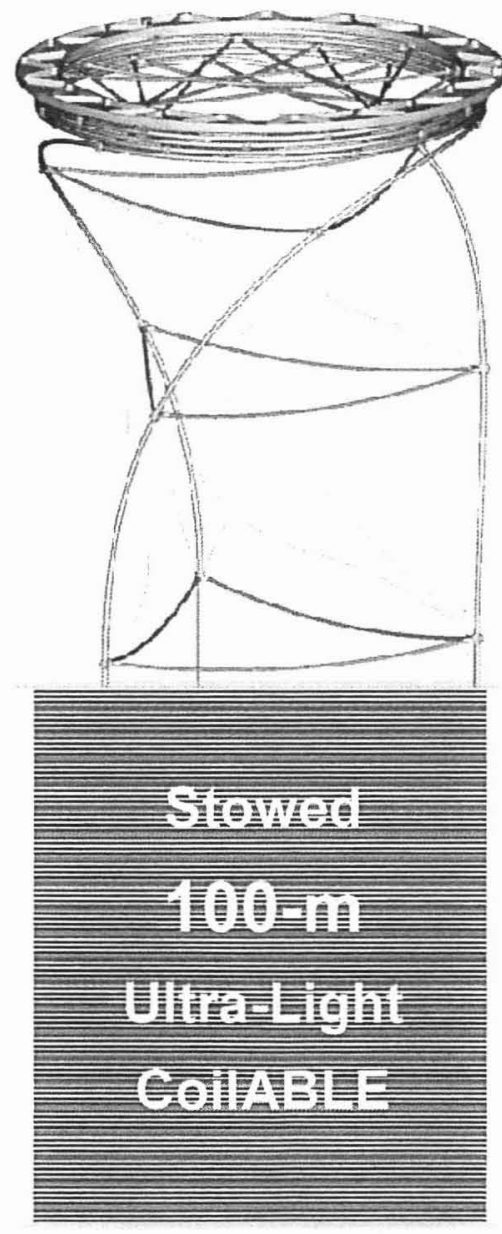




\section{SRS Solar Sail Membrane Features}

\section{Membrane Design:}

4-quadrant planar sail - 3-point sail attach with scalloped edges

- Designed determinant features, Biaxial membrane Design

- Compliant Border interface between edge cable and membrane

- Shear insensitive, Cord/Material CTE mismatch insensitive

- Thermal Gradient insensitive

\section{Sail Material: CP1 Polyimide}

- High Operating Temperature $\left(>200^{\circ} \mathrm{C}\right)$

- UV Stable

- Essentially Inert

- Soluble (Wet Process), modifiable with variety additives improve conductivity and thermal properties

\section{- 2 micron polyimide}

- Flight Proven --- flying on Numerous GEOCOM satellites

\section{Sail Construction Methods:}

A gossamer film construction similar to gusseted, reflective blankets flying on numerous GEOCOM satellites

- Scalable Construction Methods --- current system >20m

- Adhesive less Bonding Methods --- eliminates sticking and contamination risks.
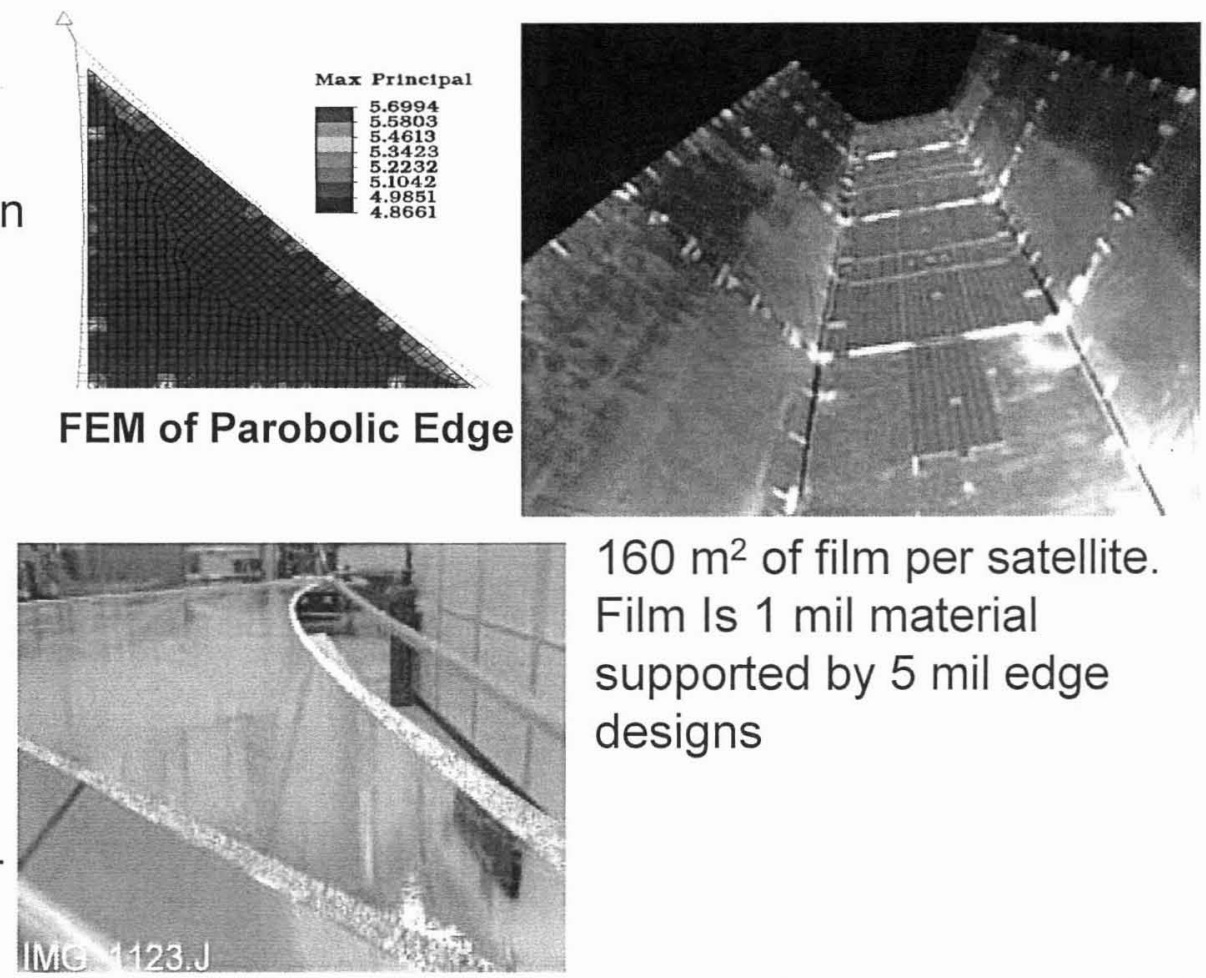

$160 \mathrm{~m}^{2}$ of film per satellite. Film Is 1 mil material supported by 5 mil edge designs

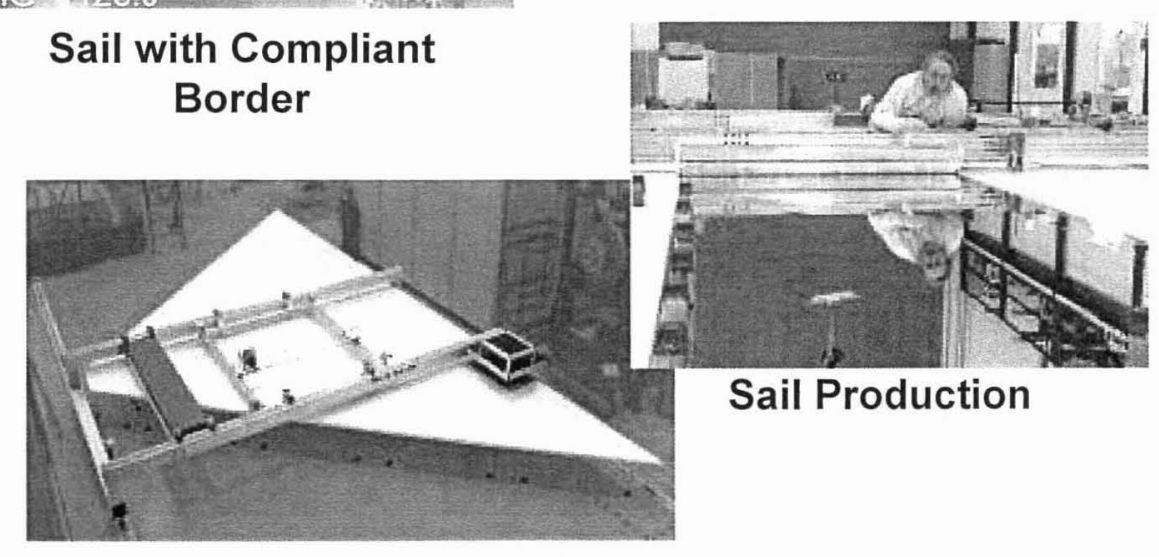

SRS CNC Seaming System 


\section{ATK Ambient Deployment at Plum Brook}

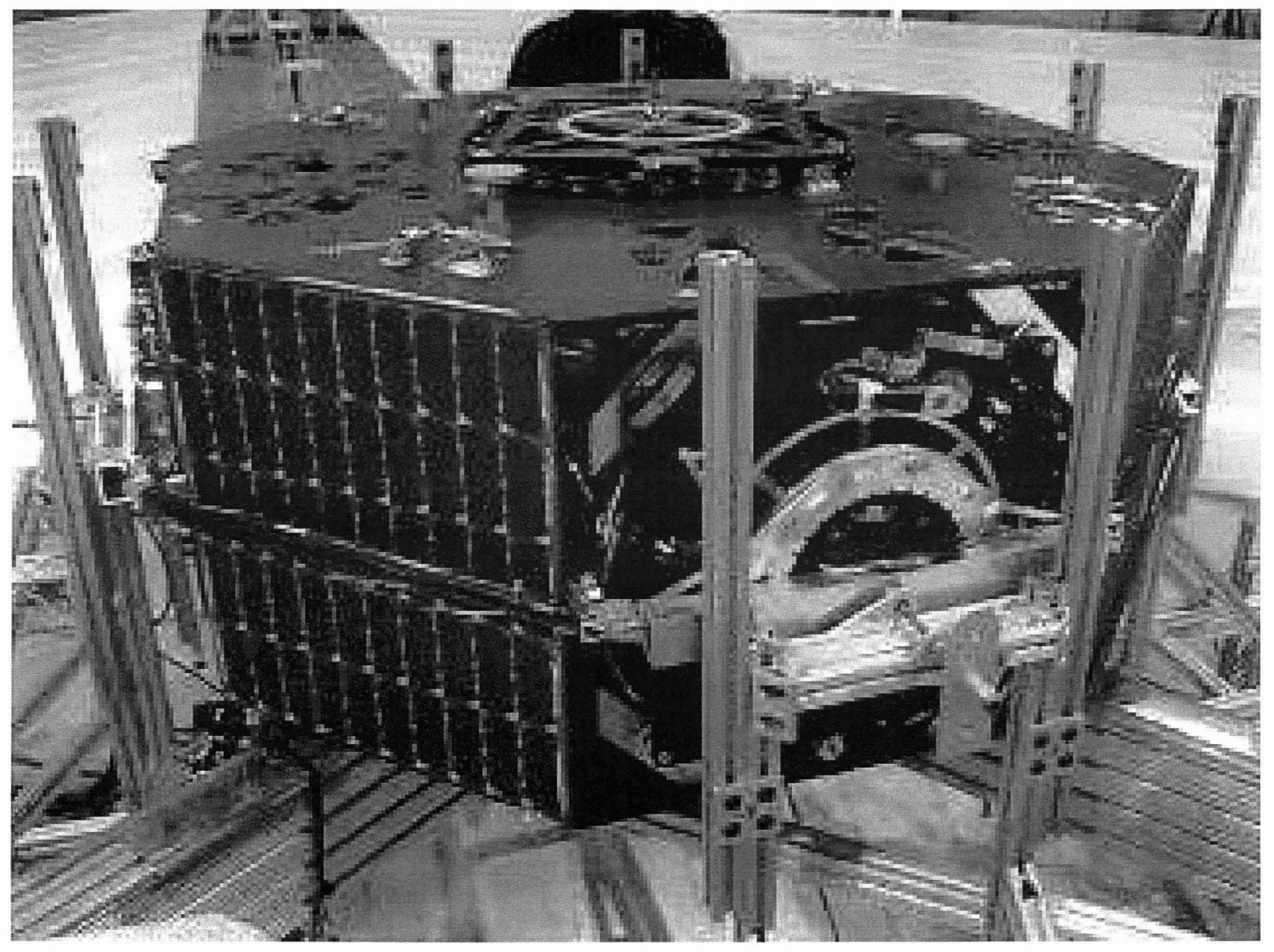




\section{L'Garde Task Summary}

•PI: David (Leo) Lichodziejewski, L'Garde, Inc.

- Proposal Team:

- L'Garde, Inc. (Tustin, CA) systems engineering and inflatable truss

- Ball Aerospace \& Tech Corp. (Boulder, CO) mission eng. \& bus design

- LaRC (Hampton, VA) sail modeling \& testing

- JPL (Pasadena, CA) mission planning \& space hazards

- Overall Strategy

- Concept Leverages ST-5 Phase A and Team Encounter experience

- Sail membrane, AL coated $2 \mu \mathrm{m}$ Mylar attached with stripped net

- Lightweight Semi-monocoque Boom With Sub-Tg Rigidization

- 4 Vane Thrust Vector Control
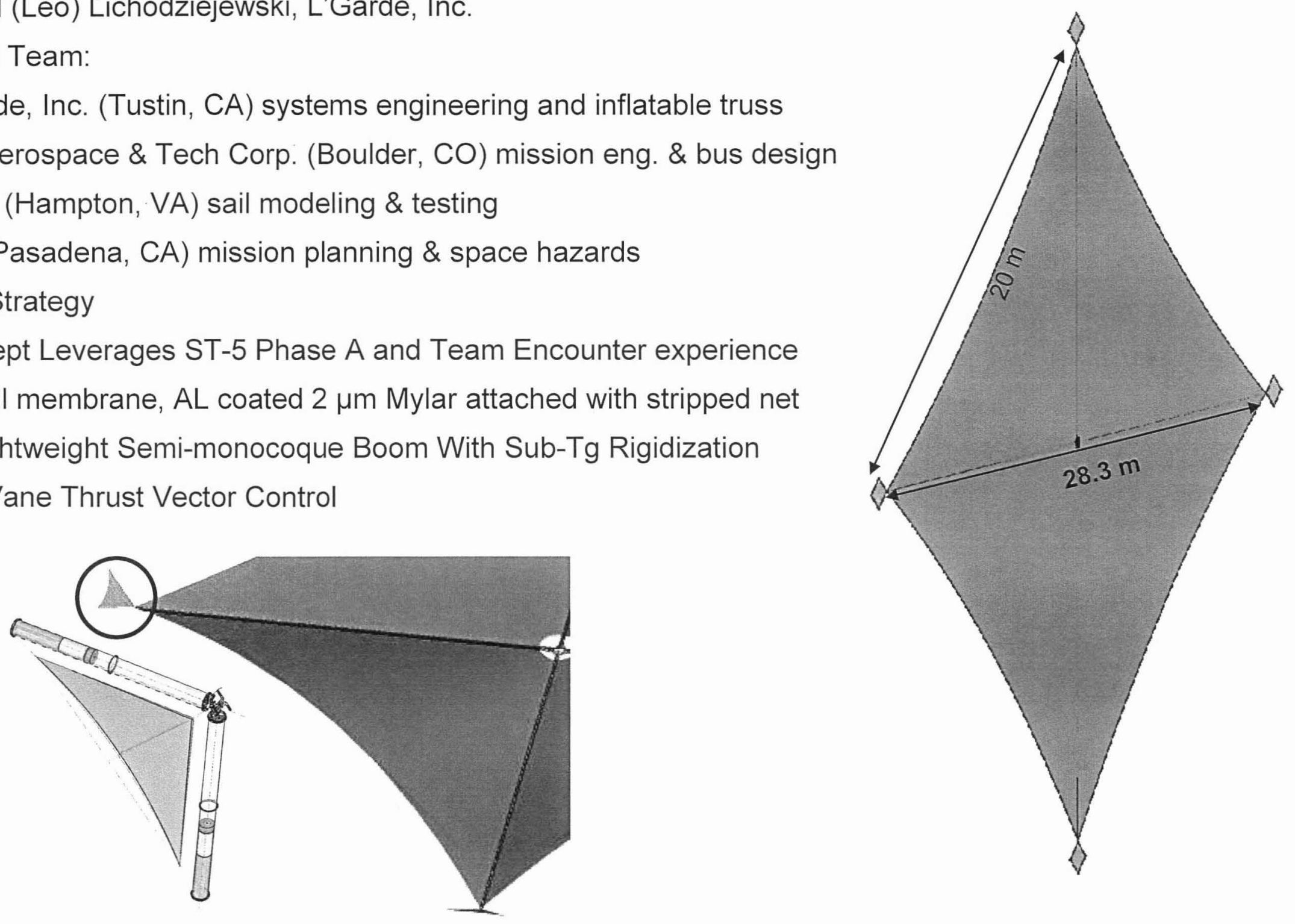


\section{Beam Design}

Load bearing longitudinal uni-directional fibers

- Fibers impregnated with sub-Tg resin (rigid below $-20^{\circ} \mathrm{C}$ )

- $0.48 \mathrm{AU}$ design requires greater fiber density to withstand loads from the increased solar flux

Spiral wrap

- Stabilizes longitudinal fibers

- Allows over-pressurization for deployment anomalies

Bonded Kapton bladder and Mylar

- Encapsulation "skin" carries shear

- Aircraft fuselage like structure

\section{Beam Structure}

- Sail structure is stressed for solar loading in one direction for mass efficiency

- Truss system comprised of mostly tension elements, minimal rigid components

- Highly mass efficient, $\sim 36 \mathrm{~g} / \mathrm{m}$ linear density

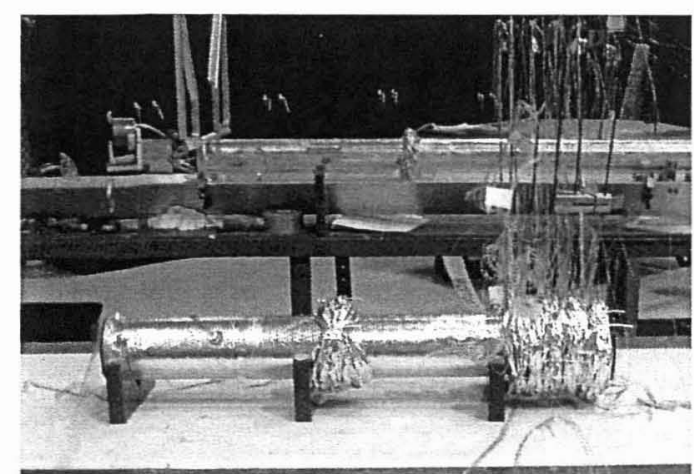

Stowed $7 \mathrm{~m}$ boom $(\sim .5 \mathrm{~m})$

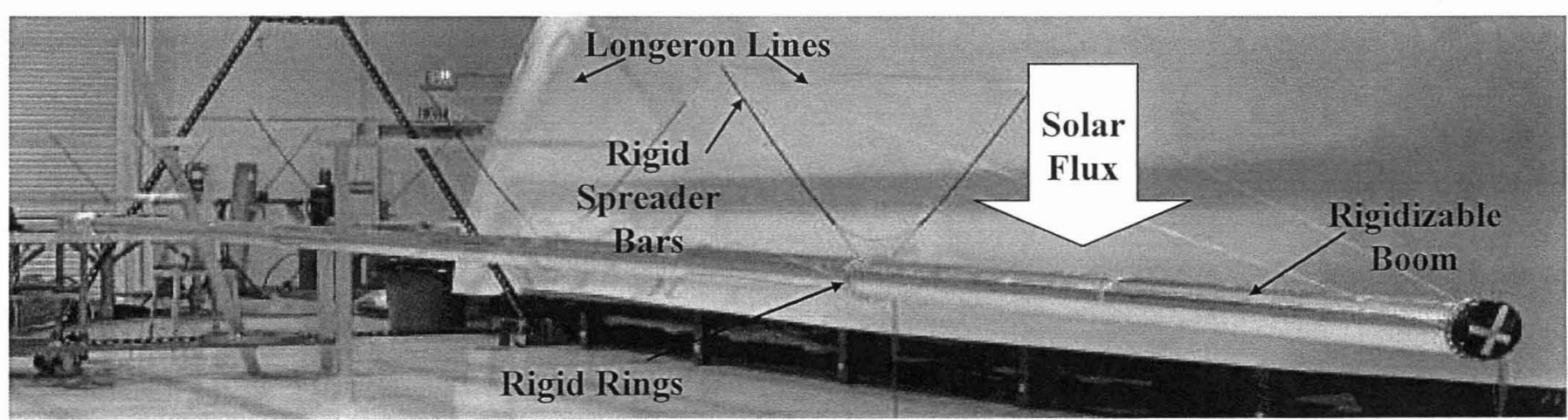

Deployed $7 \mathrm{~m}$ boom 


\section{Net/Membrane Sail Design}

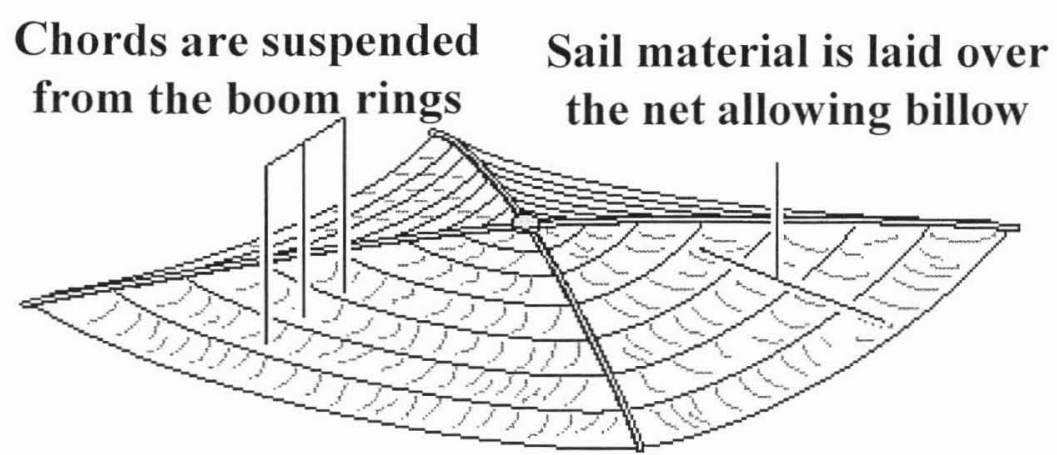

Net/Membrane Sail Schematic

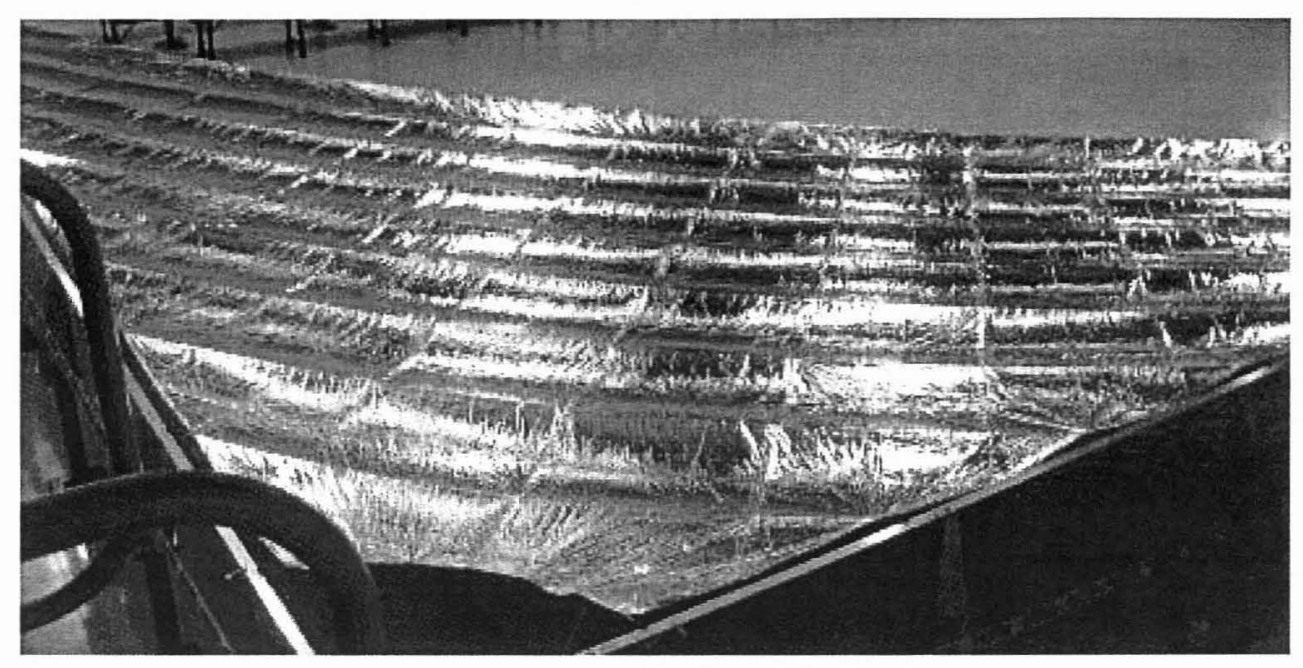

20m Sail Quadrant

\section{Net Membrane}

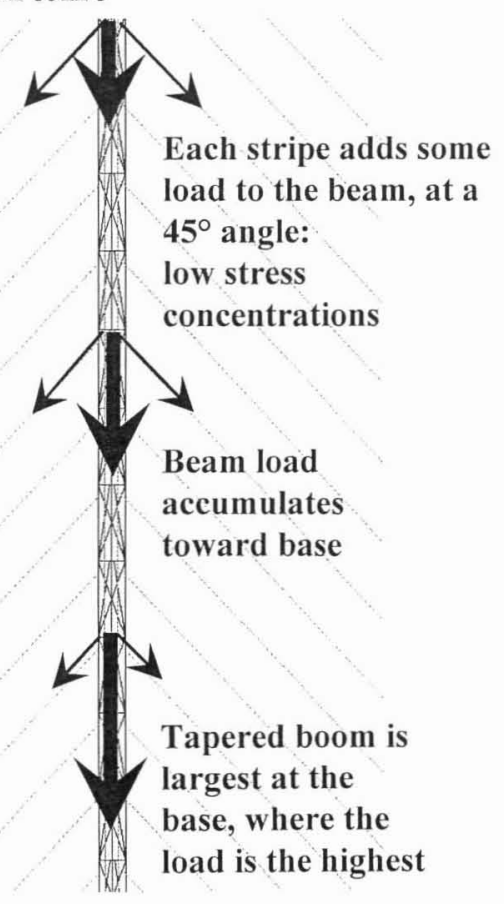

- Sail is supported by a high modulus, low CTE net with additional membrane material added to allow for thermal compliance

- Sail properties effect local billow between net members only, global sail shape is stable

\section{Advantages}

- Net defines the overall sail shape, not the membrane

- Stability and geometry of the sail is effectively decoupled from membrane properties

- Sail shape, and hence thrust vector, sailcraft stability and performance, are predictable and stable

- No high local stress concentrations in the sail, loads are transferred though the net, not the membrane

- Very scalable, larger net/membrane sails simply add additional net elements to control overall shape 


\section{L'Garde 20m GSD Vacuum Deploy}

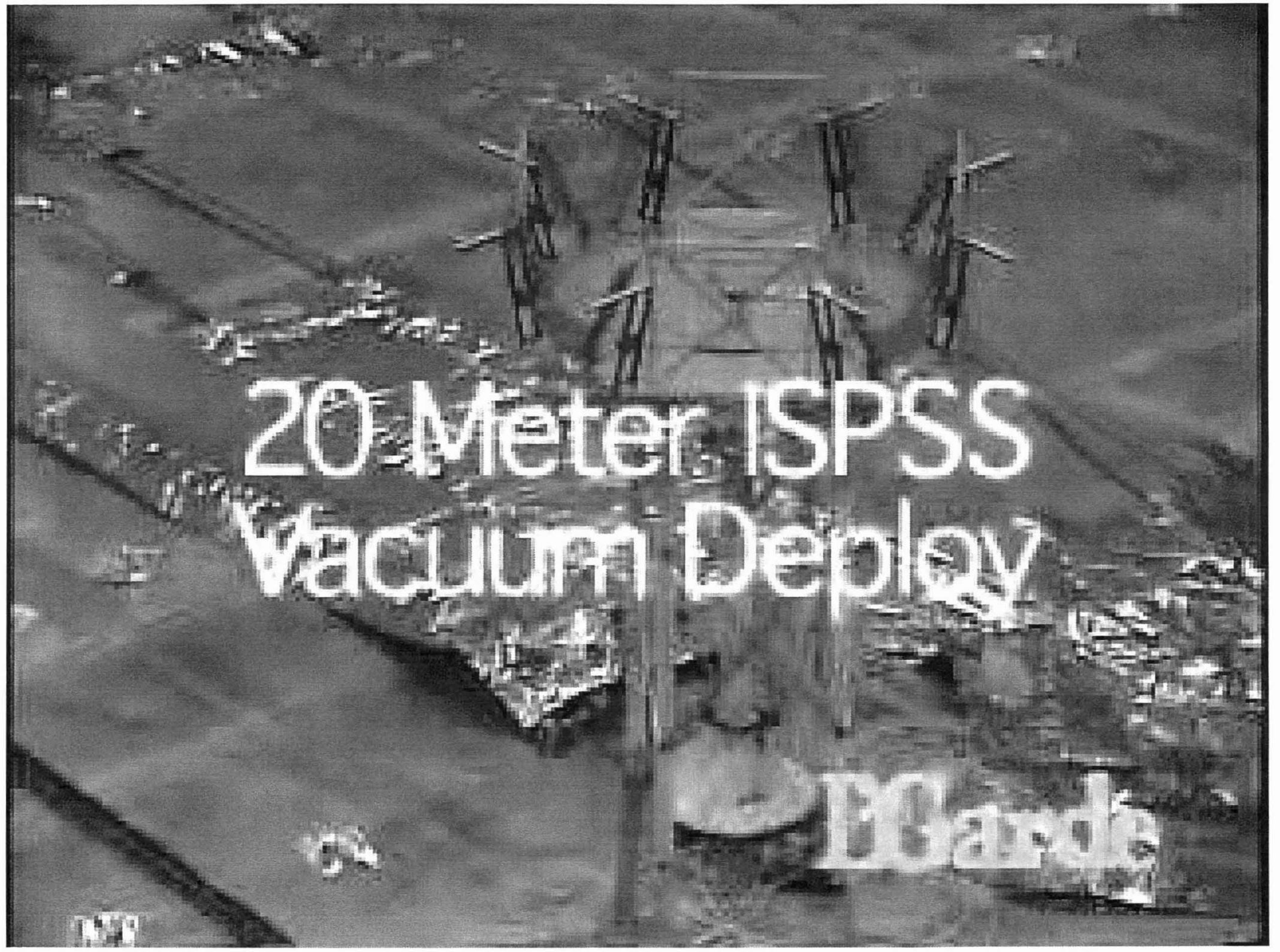




\section{FEM Analysis}

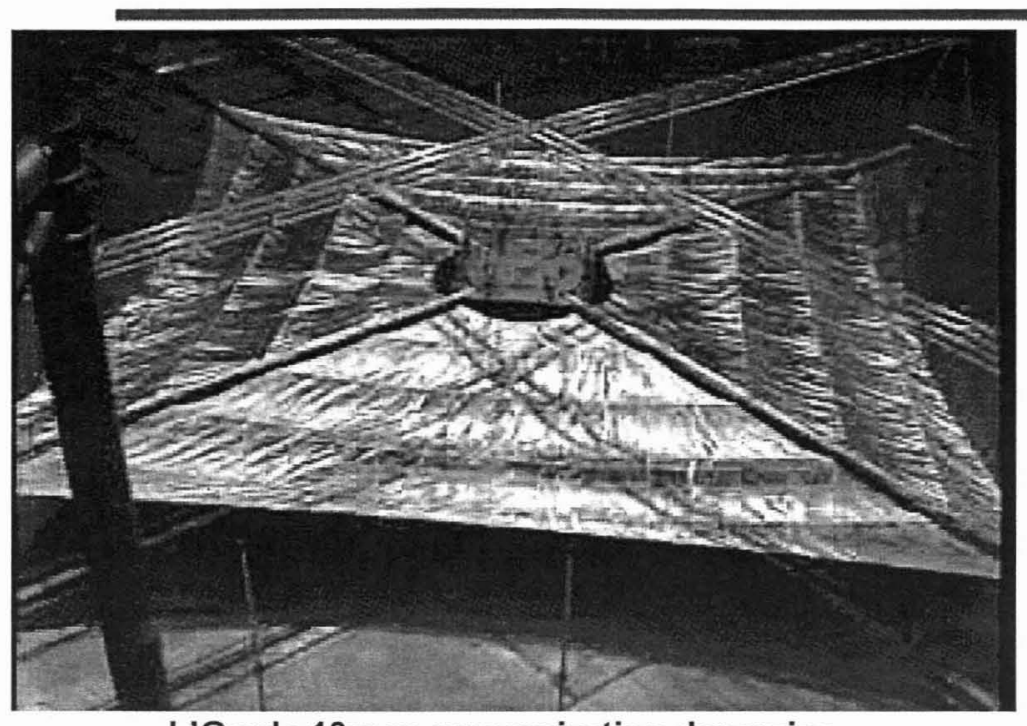

L'Garde $10 \mathrm{~m}$ re-pressurization dynamics

\section{ATK Results}

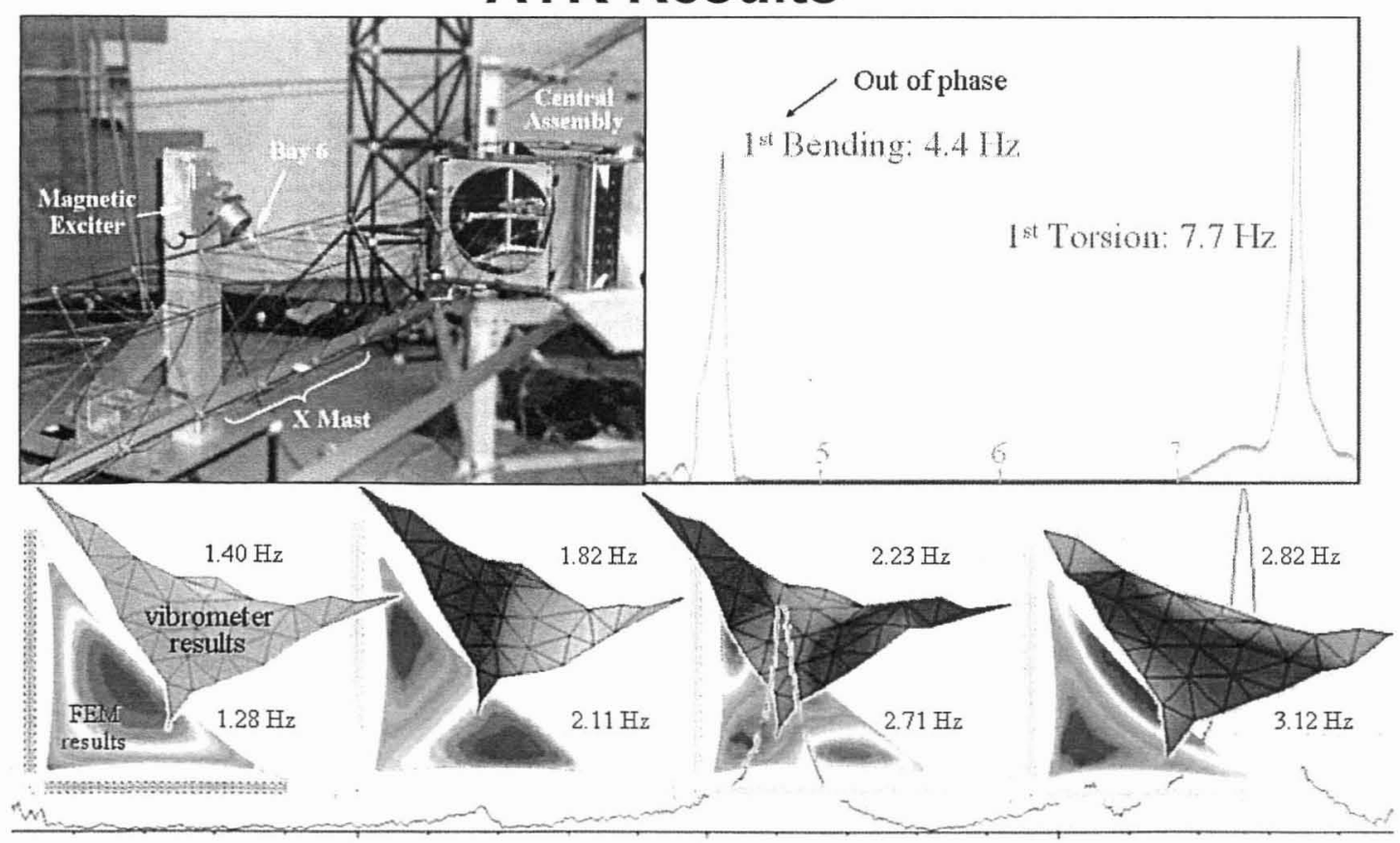

\section{L'Garde Results}

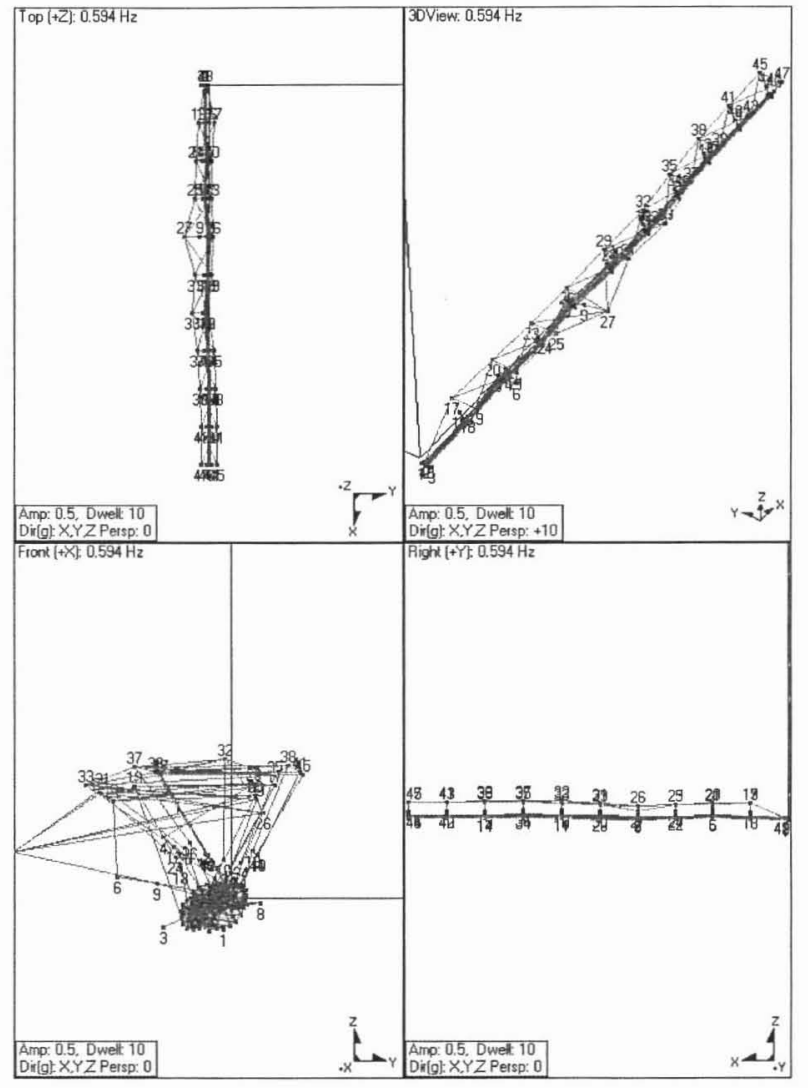

FEA Mode:

$0.83 \mathrm{~Hz}$

Test Mode 1:

$0.829 / 0.841 \mathrm{~Hz}$

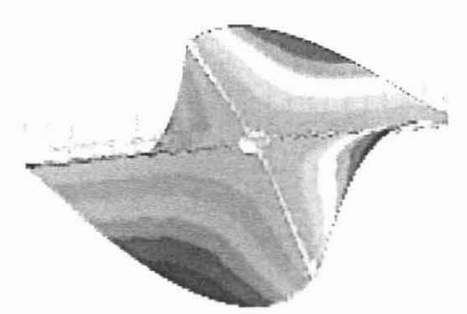




\section{Additional Tasks}
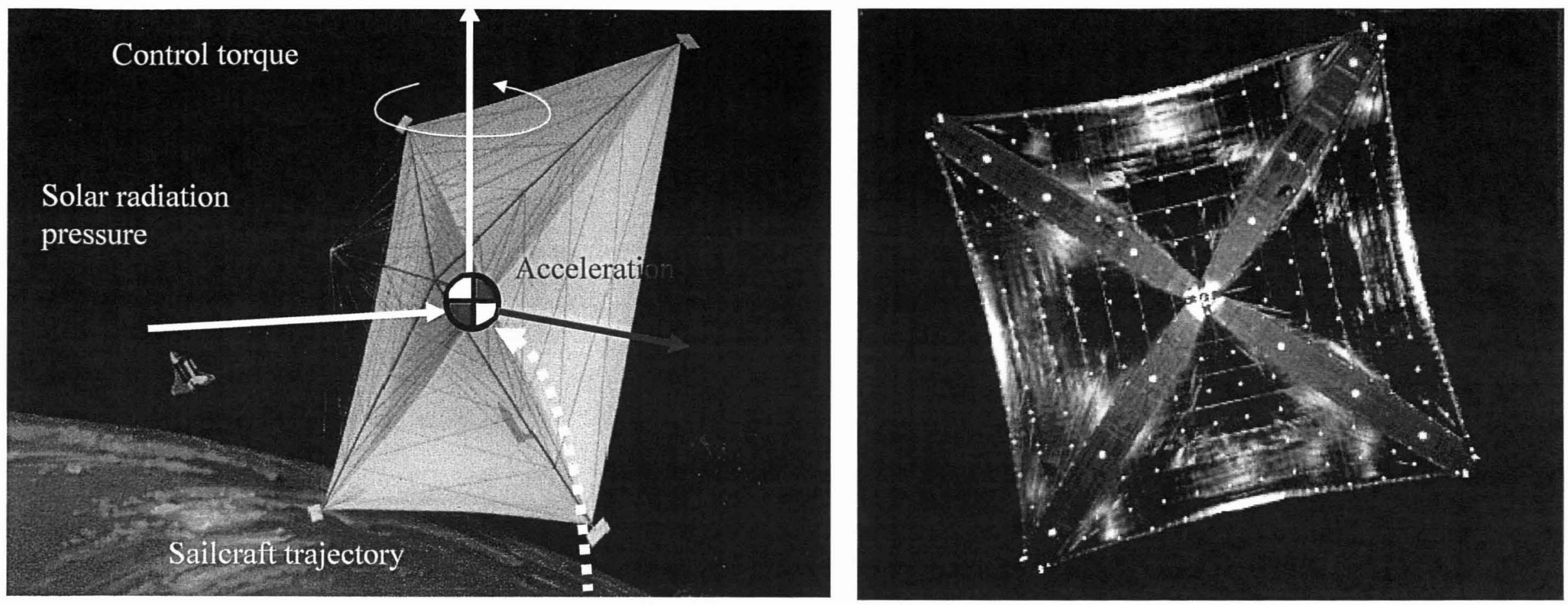

Solar Sail Spaceflight Simulation Software (S5)

Develop an integrated simulation and analysis software tool for optimal design of solar sail trajectories and for evaluation of guidance navigation and control strategies.

Optical Diagnostic System (ODS) Develop a lightweight integrated instrumentation package to allow measurement of sail shape, tension and temperature; boom \& sail vibration modes and stress; and deployment monitoring. 


\section{Additional Tasks - cont.}

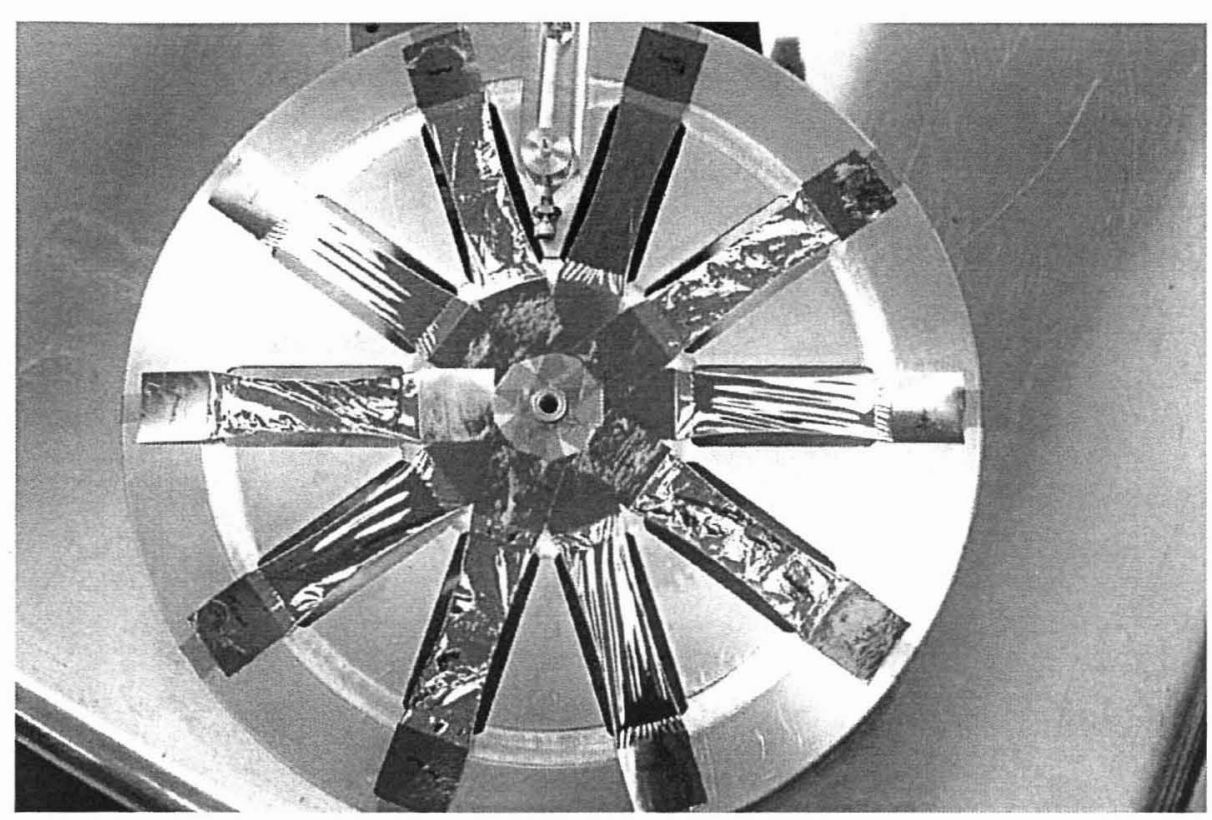

Samples prior to UV exposure

Material Testing

Characterize engineering performance of candidate SS materials for both a Solar Sentinel and Solar Polar Imager, gauging material property tolerances after exposure to emulated mission-specific charged-particle and micrometeoroid environments.
Able's Solar Sail Mast with a Trim Control Mass (TCM), Roll spreater Bars (RSBs), and micropPTs
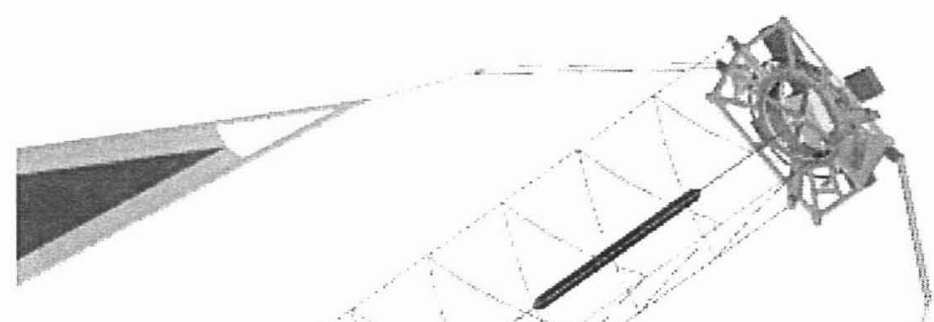

Development of a Lightweight Robust SACS and a Software Toolkit for Solar Sails

Develop of a highly integrated, low cost, low mass, low volume, and low power attitude determination and control system and develop a high-fidelity multi-body modeling and simulation software toolkit. 


\section{Additional Tasks - cont.}

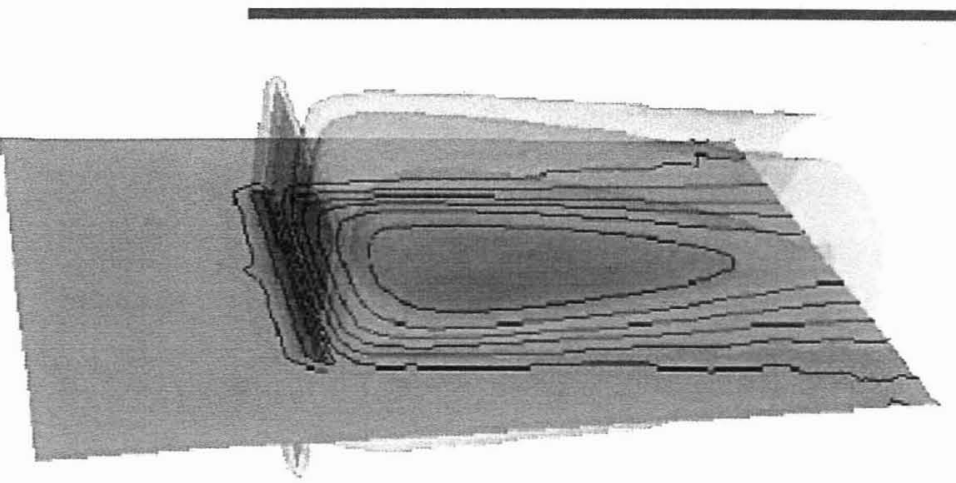

VT Plasma Flow Model of sail in the solar wind with the potentials normalized by $0.25 \mathrm{Te}$

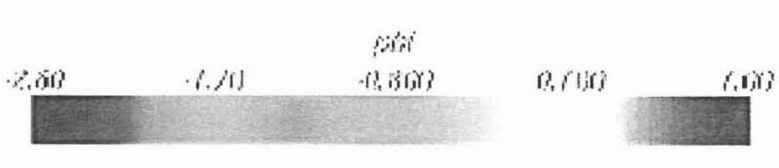

Sail Charging Analysis

Development of environmental and sail configuration models and design guideline criteria for solar sails. Conduct laboratory assessment of potential for destructive charging fields and arcing events within the sail and surrounding environment.

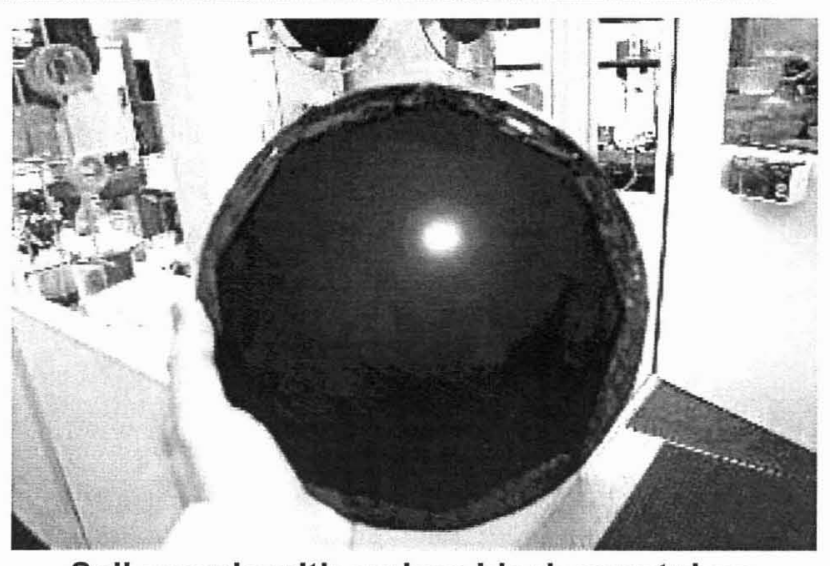

Sail sample with carbon black nanotubes Advanced Manufacturing Technologies Develop and refine the technology of sail assembly for manufacturing large monolithic sails, improving membrane coating processes and technologies

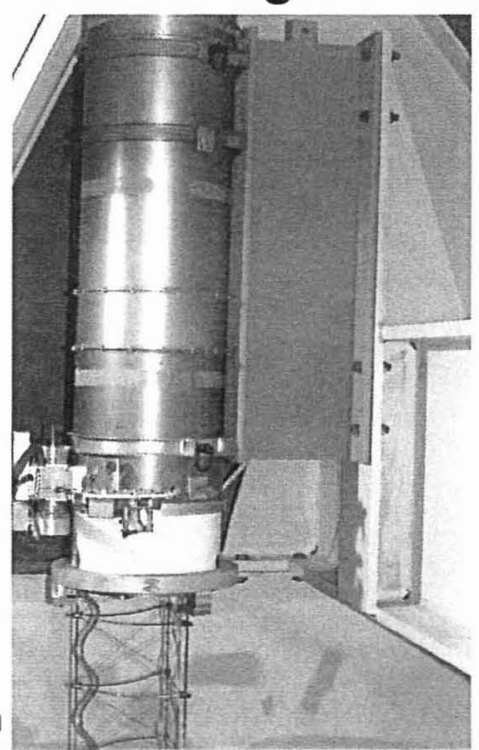




\section{Solar Sail Propulsion Notables}

- Designed, built, delivered, and safely tested in a ground environment two $20 \mathrm{~m}$ solar sail systems using different technologies

- Subjected materials to high doses of radiation verifying on-orbit life time characteristics

- Developed a flight mechanics simulation capable of modeling non-Keplerian orbits

- Conducted static and dynamic response tests and multiple deployments of two 400 square meter sails from a one cubic meter box at a high vacuum in the largest horizontal space test chamber in the world (Plum Brook). $500 \mathrm{~Gb}$ of data generated.

- Subjected stowed systems to launch loads and ascent vent tests prior to deployment.

- Measured Modal Test Frequencies matched predicted values to within ten percent.

- Developed repair techniques for membranes and booms.

- Developed and used in test the largest high resolution photogrammetric shape measurement system in the world.

- Developed a mission concept to extend warning times to Earth for damaging solar events from 30 minutes to 90 minutes.

- Successfully applied conventional finite element modeling techniques to large area gossamer space structures.

- Determined the extent to which gossamer structures can be verified by test on the ground.

- Identified a tendency for torsional dynamic modes in the booms to migrate to bending modes.

- Discovered that wrinkles and other small defects have minimal impact on propulsion performance.

- Discovered significant robustness against spacecraft charging. 


\section{TRL Assessment Methodology - 10 meter}

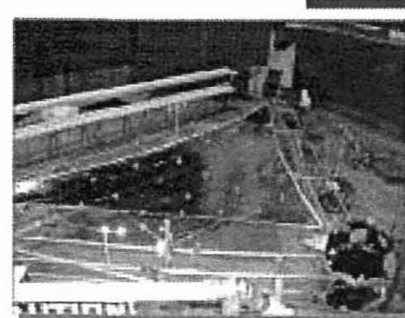

ATK 10M System

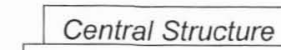

Sails
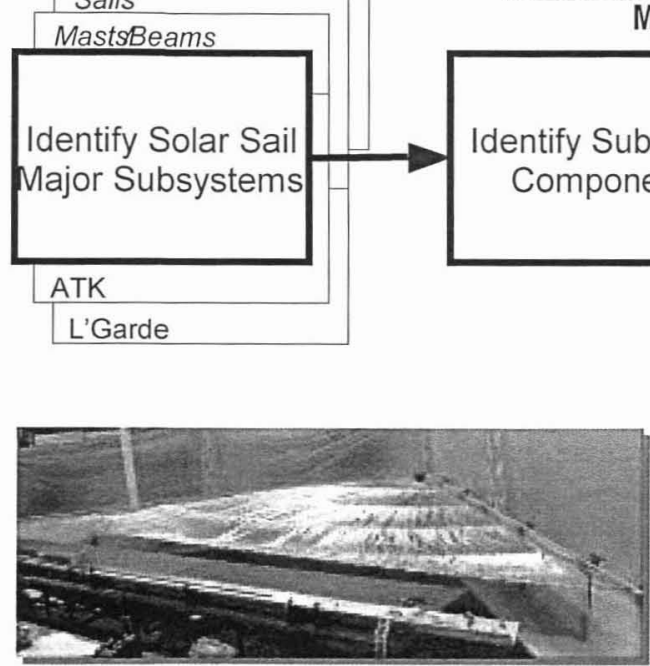

Sails

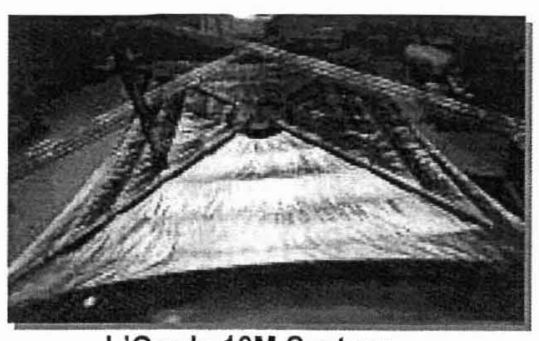

L'Garde 10M System

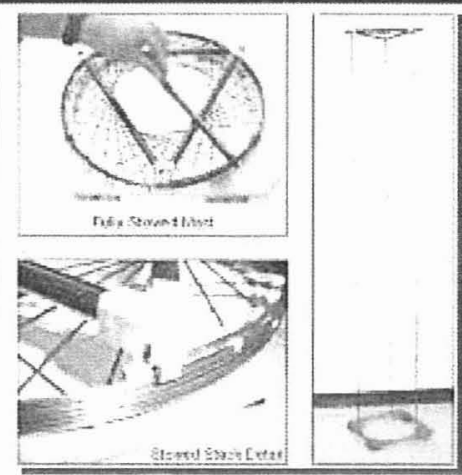

Masts Identify Subsystem Components

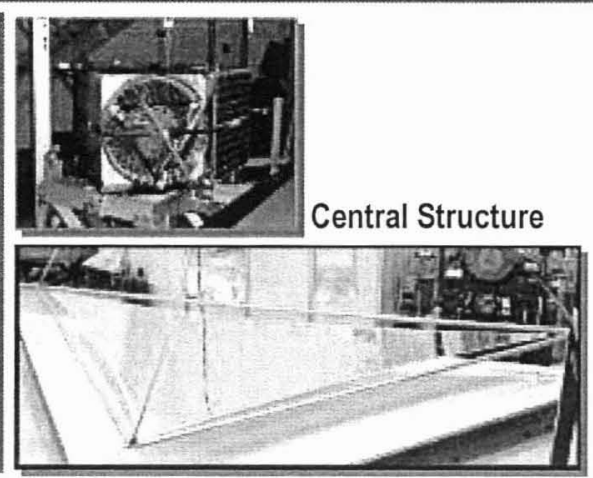

Sails
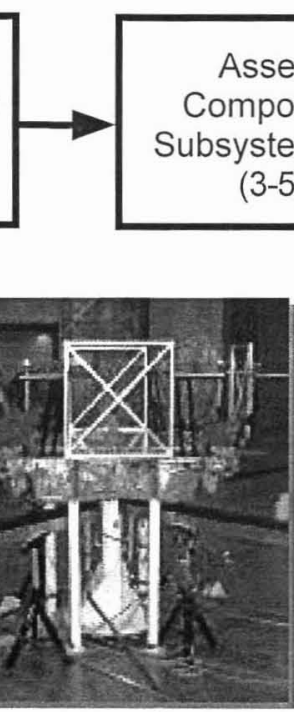

Central Structure

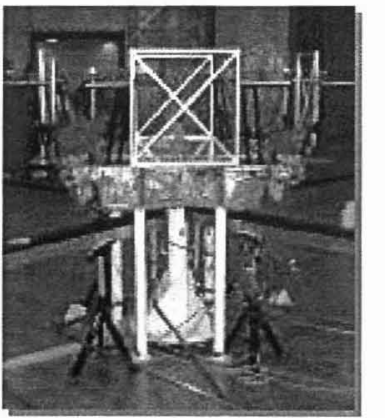

Beams

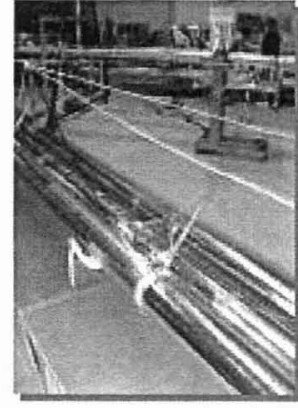

Assess (3-5)

\begin{tabular}{|c|c|c|}
\hline $\begin{array}{l}\text { L'Garde Subsystem } \\
\text { Components }\end{array}$ & $\begin{array}{c}\text { TRL } \\
5\end{array}$ & $\begin{array}{c}T R L \\
6\end{array}$ \\
\hline Mast Components & & $58 \%$ \\
\hline Boom and Rigidization System & $63 \%$ & \\
\hline Inflation Subsystem & $63 \%$ & \\
\hline Heater Wires & $100 \%$ & \\
\hline Insulation & $75 \%$ & \\
\hline End Caps & $100 \%$ & \\
\hline Spreader System and Rings & $63 \%$ & \\
\hline Cat's Cradle & $63 \%$ & \\
\hline Models Replicate Performance & $75 \%$ & \\
\hline Analytical Predictions Complete & $100 \%$ & \\
\hline Sail Components & & $83 \%$ \\
\hline Material \& Coatings & $75 \%$ & \\
\hline Integrated Ripstop & $63 \%$ & \\
\hline Grounding straps & $63 \%$ & \\
\hline Striped Net & $63 \%$ & \\
\hline Models Replicate Performance & $88 \%$ & \\
\hline Analytical Predictions Complete & $94 \%$ & \\
\hline Central Structure Components & & $67 \%$ \\
\hline Carrier Assembly & $75 \%$ & \\
\hline Doors \& Actuators & $100 \%$ & \\
\hline Spacecraft Interface & $75 \%$ & \\
\hline Models Replicate Performance & $50 \%$ & \\
\hline Analytical Predictions Complete & $50 \%$ & \\
\hline Model Validation & & $58 \%$ \\
\hline $\begin{array}{c}\text { Packing/Flight Design/Interface } \\
\text { Effects Advancement }\end{array}$ & & $72 \%$ \\
\hline
\end{tabular}

\begin{tabular}{|c|c|c|}
\hline ATK Subsystem Componen & $\begin{array}{c}T R L \\
5\end{array}$ & $\begin{array}{c}T R L \\
6\end{array}$ \\
\hline Mast Components & & $61 \%$ \\
\hline Battens & $88 \%$ & \\
\hline Longerons & $88 \%$ & \\
\hline Diagonals & $88 \%$ & \\
\hline Corner Groups & $100 \%$ & \\
\hline Halyards & $100 \%$ & \\
\hline Lanyards & $100 \%$ & \\
\hline Deployment Motor/Mechanisms & $88 \%$ & \\
\hline Models Replicate Performance & $75 \%$ & \\
\hline Analytical Predictions Complete & $100 \%$ & \\
\hline Sail Components & & $61 \%$ \\
\hline Material \& Coatings & $88 \%$ & \\
\hline Tear Resistant Design & N/A & \\
\hline $\begin{array}{l}\text { Deployments Sequencers } \\
\text { (Attachment points) }\end{array}$ & $93 \%$ & \\
\hline Grounding straps & $75 \%$ & \\
\hline Compliant Border & $93 \%$ & \\
\hline Models Replicate Performance & $93 \%$ & \\
\hline Analytical Predictions Complete & $100 \%$ & \\
\hline Central Structure Component & & $53 \%$ \\
\hline Carrier Assembly & $50 \%$ & \\
\hline Doors\& Actuators & $75 \%$ & \\
\hline Spacecraft Interface & $38 \%$ & \\
\hline Drum & $75 \%$ & \\
\hline Models Replicate Performance & $0 \%$ & \\
\hline Analytical Predictions Complete & $0 \%$ & \\
\hline Model Validation & & $67 \%$ \\
\hline $\begin{array}{c}\text { Packing/Flight } \\
\text { Design/lnterface Effects } \\
\text { Advancement }\end{array}$ & & $58 \%$ \\
\hline
\end{tabular}




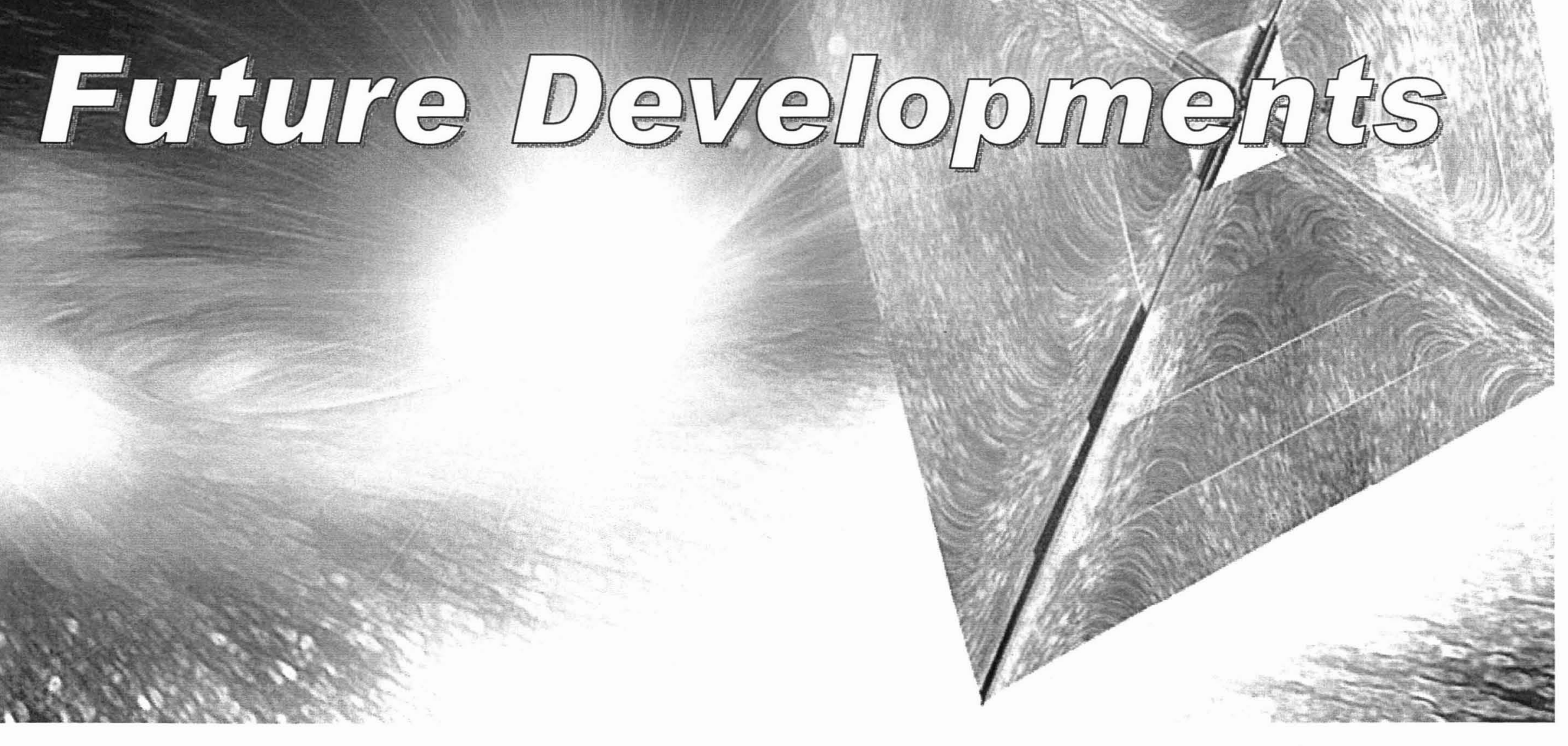




\section{Heliophysics Draft Roadmap - 5/2006}
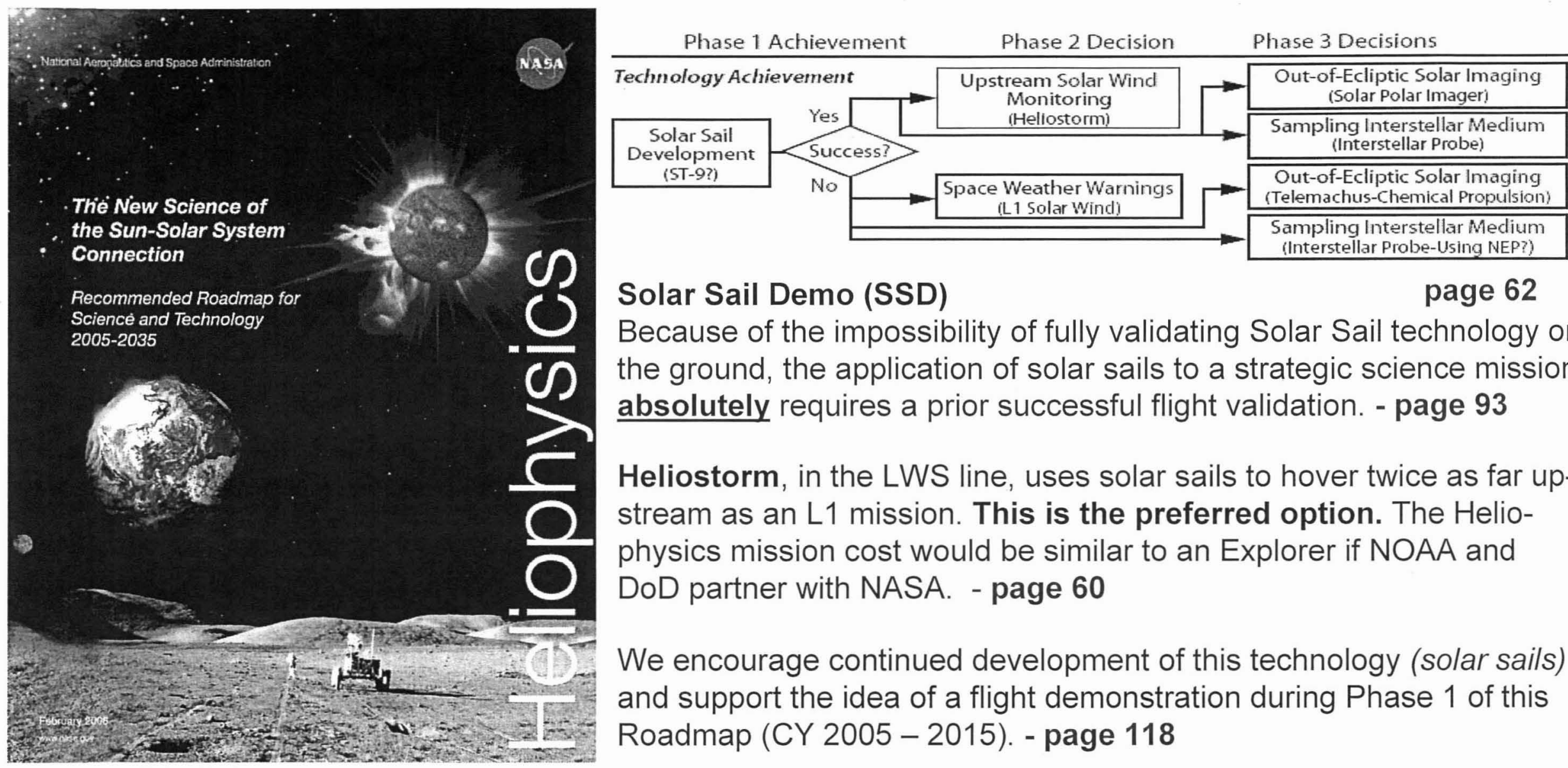

Solar Sail Demo (SSD)

page 62

Because of the impossibility of fully validating Solar Sail technology on the ground, the application of solar sails to a strategic science mission absolutely requires a prior successful flight validation. - page 93

Heliostorm, in the LWS line, uses solar sails to hover twice as far upstream as an L1 mission. This is the preferred option. The Heliophysics mission cost would be similar to an Explorer if NOAA and DoD partner with NASA. - page 60

We encourage continued development of this technology (solar sails) and support the idea of a flight demonstration during Phase 1 of this Roadmap (CY 2005 - 2015). - page 118

Progress in key areas of Heliophysics science requires access to unique vantage points and in some cases, non-Keplerian orbits. For example, imaging of the Sun's polar regions requires a high-inclination, heliocentric orbit. Conventional technology would require either 5 years of solar electric propulsion and multiple Venus flybys just to reach a $38^{\circ}$ inclination in the inner heliosphere (as for ESA's Solar Orbiter) or a Jovian gravity assist and conventional propulsion to provide an eccentric $0.25 \times 2.5 \mathrm{AU}$ polar orbit (as for our future Telemachus mission). Neither means is as efficient or cost effective as solar sail technology. - page 97 NOTE: Emphasis added to original text 


\section{TRL Completion Logic}

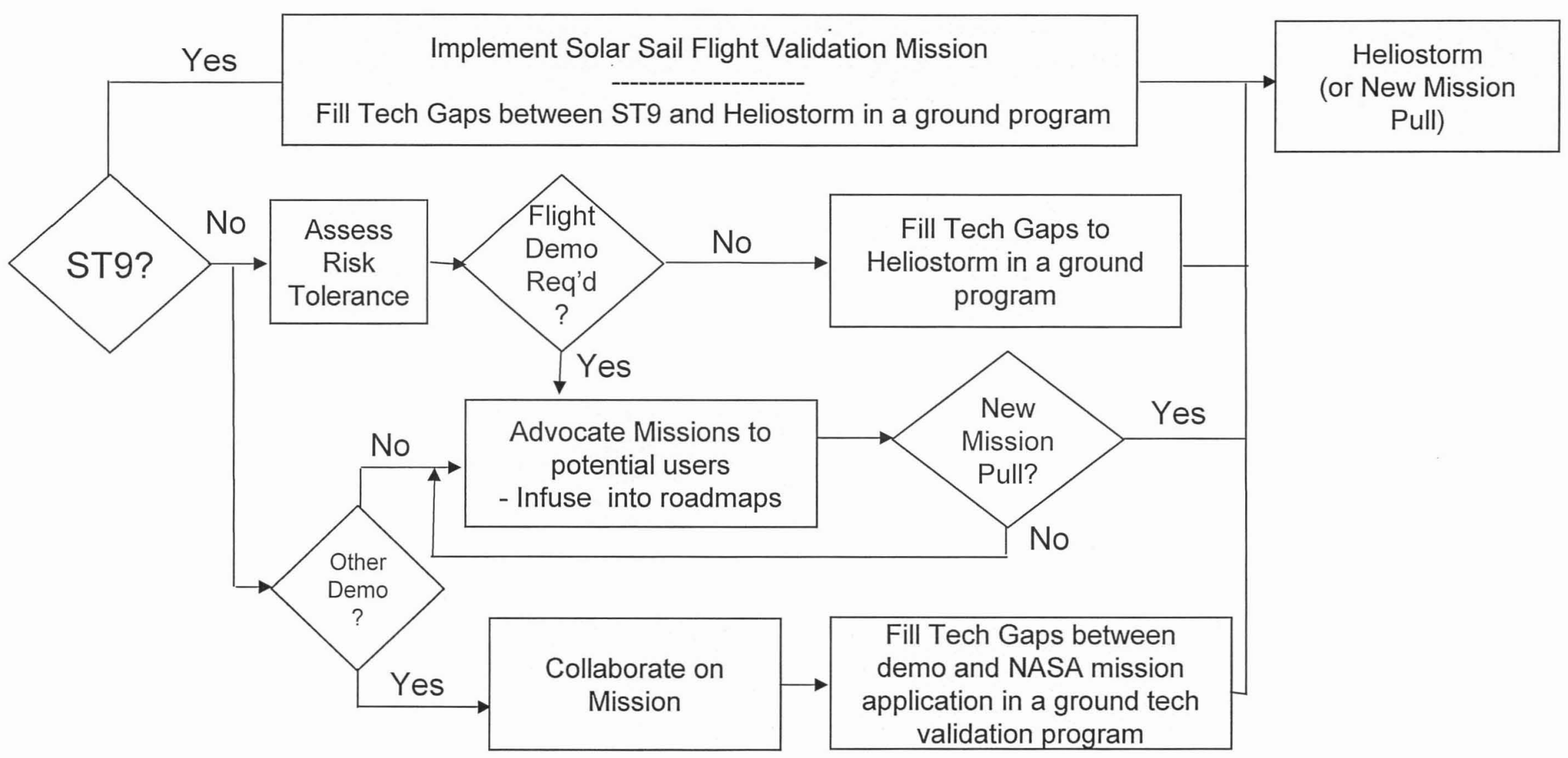




\section{Growing Number of Solar Sail Activities}

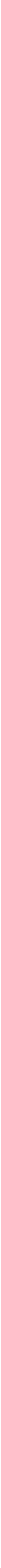




\section{Solar sail Propulsion Technology Advantages}

\section{Low Cost to Develop \& Operate}

\section{Simple}

- Few moving mechanical parts

- Low complexity

- Quasi-Steady State

- Small in size - payloads and stowed system

- Autonomous, robotic
- Safe

- No High temperatures

- No High pressures

- No High Power

- No Toxic fuels

- Loads are vanishingly small
- Technology Benefits

- No propellants required

- Low system complexity (challenge is scaling to large area with ultra-low density)

- Low environmental impact on payload

- Enables access to previously inaccessible orbits (e. g., non-Keplerian, fixed reference, and high inclination orbit changes)
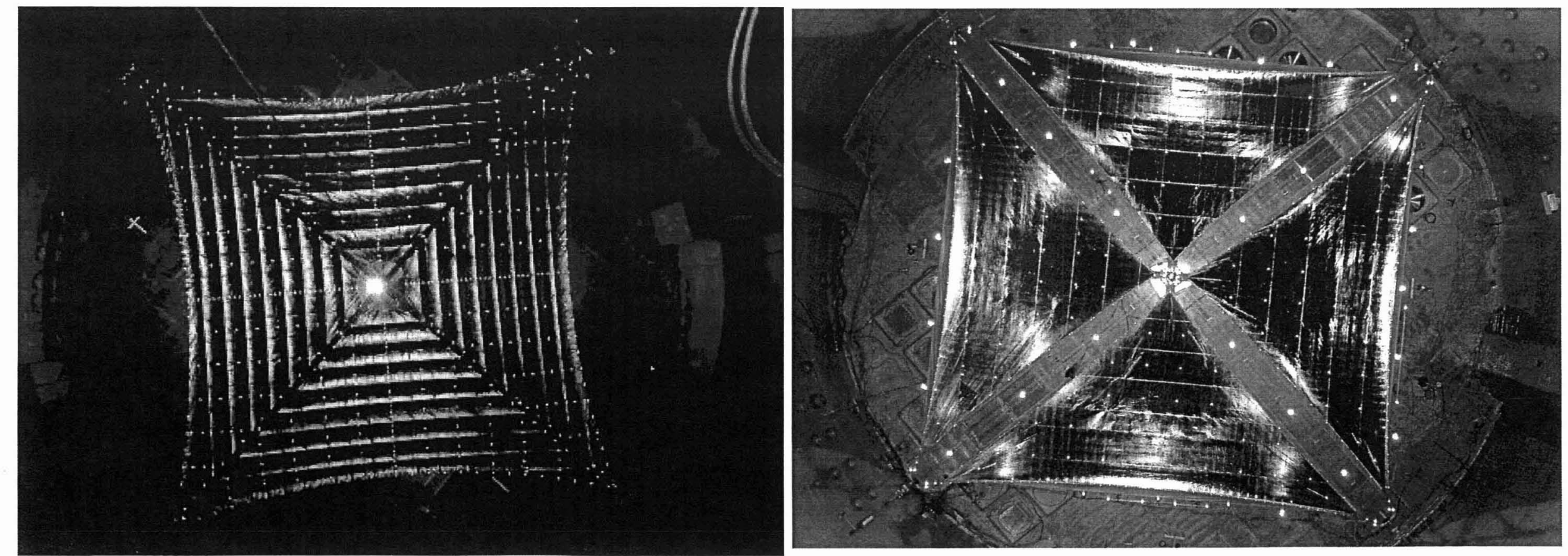


\section{For additional information on the Solar Sails Propulsion}

task areas within the In-Space Propulsion Technology Project, please contact:"

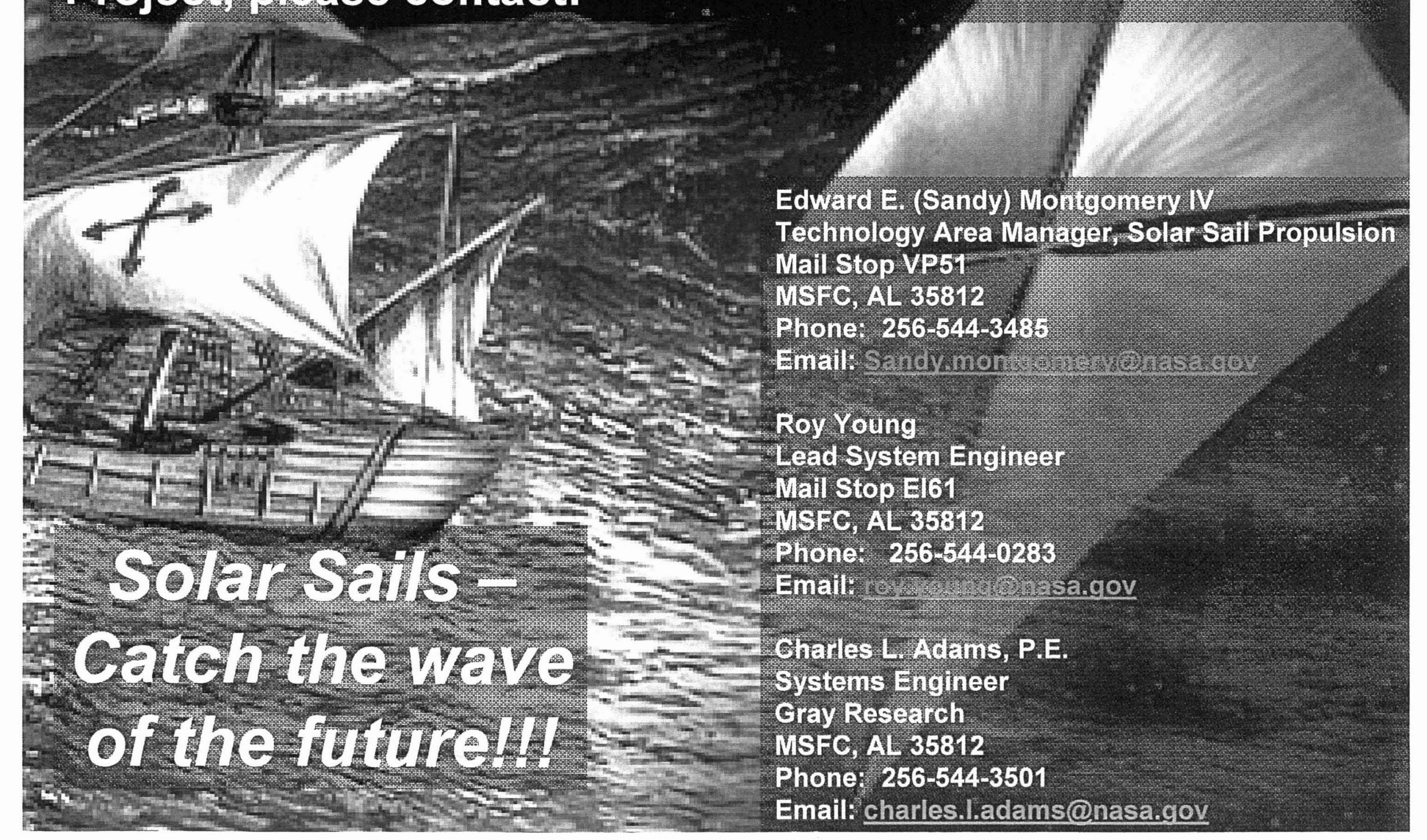




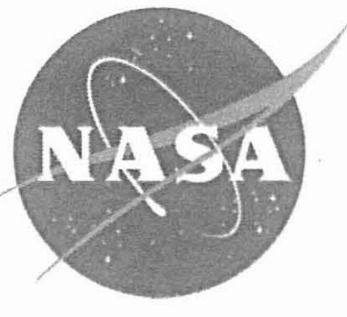

www.nasa.gov 